Review

\title{
Biomechanically Inspired Machines, Driven by Muscle Like Acting NiTi Alloys
}

\author{
${ }^{1}$ Antonio Apicella, ${ }^{1}$ Raffaella Aversa and ${ }^{2}$ Florian Ion Tiberiu Petrescu \\ ${ }^{1}$ Advanced Material Lab, Department of Architecture and Industrial Design, \\ Second University of Naples, 81031 Aversa (CE), Italy \\ ${ }^{2}$ ARoTMM-IFToMM, Bucharest Polytechnic University, Bucharest, (CE), Romania
}

Article history

Received: 16-04-2018

Revised: $13-05-2018$

Accepted: 22-05-2018

Corresponding Author:

Florian Ion Tiberiu Petrescu

ARoTMM-IFToMM, Bucharest

Polytechnic University,

Bucharest, (CE), Romania

Email: scipub02@gmail.com

\begin{abstract}
The Shape of the Memory Alloy (SMA) is a very promising class of metallic materials with interesting non-linear properties such as Pseudo-Elasticity (PE), memory (MEM) and damping capacity due to high mechanical hysteresis and internal friction. Research shows a bioinventory approach to Shape Memory Alloy (SMA) design, a class of intelligent materials capable of reacting to a pulse (thermal for SMA) with shrinkage. Martensitic transformations in shape-effect crystals under the effect of external forces lead to large deformations of an inelastic nature. In some materials, these reversible deformations are in the range from one digit to at least two digits. The recovery of accumulated inelastic deformation and, as a consequence, the return to the original shape of the body can occur both in the process of unloading at a constant temperature (superelastic effect) and in heating (a form memory effect). Both effects are exciting with regard to their application in compact servomotors when heating the effect of shape memory generates stresses in most materials. If the shape memory alloy faces any shape recovery resistance, it can generate reactive force. The importance of this effect in technical applications is that the reactive force significantly exceeds the force that caused the initial change of shape. This can be used to produce a useful mechanical work. The biomechanically inspired machine that is discussed in the paper refers to pairs of muscle antagonists that are part of the skeletal muscles and are usually arranged in opposition so that a group of muscles contractors another group that relaxes or prolongs. The study proposes a model, a solution not only to design a specific application but also to provide an approach to be used for a wide range of adaptive applications (switching windows, intelligent shadows, parking and urban shelters, etc.). The shape changes in response to various external stimuli. The use of pairs of antagonists provides a solution for SMA-optimized systems where the main and proven advantages are: Easier and quicker shape change, the energy requirement for system operation, lower costs for SMA training and lack of overheating problems.
\end{abstract}

Keywords: Biomechanics, Biomaterials, Shape Memory Alloy, Biomechanically Inspired Machine

\section{Introduction}

Neurological disorders are a large number of diseases that affect the Central Nervous System (CNS). Consequently, the ability to move and control involuntary limb actions is affected, resulting in disability, loss of quality of life and functional independence.
Among neuromuscular disorders, this work will refer to those that depend on the superior motor neuron lesions (UML or corticospinal tract lesions) of various etiologies (stroke, traumatic brain injury, arteriovenous malformations, anoxia, etc.) and some Movement Disorders (MD, for example, tremor, dystonia, dyskinesia) caused by alteration of normal basal ganglia. 
Previous share symptoms similar to those of the engine, of which the most relevant is a complete or incomplete paralysis from various areas of the body, with stiffness, muscle contractions, hypertonia and spasticity; the latter displays a phenomenology that is more varied but is often characterized by phasic insurgency or involuntary tonic movements of different sizes, duration, frequency, location and direction anomalies of posture. Lymph nodes (striatum, pallidum and related structures, including nigra and subthalamic nucleus), in fact, along with the cerebellum, plays an important role in the control of muscle tone, posture and coordination of movement by virtue of their connections, via thalamocortical, corticospinal and other coral progeny.

Physical rehabilitation is fundamental to promoting the recovery of lost functions in all these neurological disorders. Although the diagnosis and etiology of the disease are important and can be informed the probable range of problems and the natural history of each disease, individual disability manifestations are equally fundamental in defining patients' needs during rehabilitation. Therapy is often multimodal, including manipulation by physical therapists, orthotics, robotic therapy, active exercises and use drugs. All these actions, together, aim at restoring the normal features of the muscles and joints, control of volunteer patients, segmented functionality, pregnancy orientation and eventually personality and social independence. The relative weight of each treatment is strongly dependent on clinical settings of single patients so that the overall plan is personalized. Besides, maybe to be issues that affect the choice and effectiveness of some of the standard therapeutic protocols, such as individual side effects of the drug, intractability of some districts (e.g., due to pain), limited human time physical therapy and limitations in the use of robotic devices due to specific patient failures.

It is especially interesting to focus on the development of new devices that support physical use neurological treatment and neuromuscular rehabilitation because innovative devices can help expand the set of treatment approaches now available, allowing treatment of several patients with specific characteristics and limiting the inapplicability of certain types of therapy due to general or individual adverse effects. Applying this type of treatment is rather broad and widespread for UML-derived spastic syndromes because the fight against insurgency and chronic illness is essential to protect the possibility of functional recovery. Orthotics have a more limited use in dynamic motion disorders, although for some of them (e.g., tremor and dystonia), this type of device can be used, especially when other methods prove to be useless. Some of the issues related to the practical application of orthoses in treating MD patients depend on the fact that they often do not have sufficient aesthetic elements (appearance, size and form), cosmetics and functionality for people with a daily social life and less or less independent. Another topic to be considered in this study is the use of passive mobilization of the limbs as a means of acting positively for the maintenance or recovery of tissue properties in UML and to ensure a continuous proprioceptive brain and the somato-sensory brain in the disease phase chosen at the beginning of the event). While the importance of robotic devices for improving physical therapy and promoting better functional recovery has been recognized in the past, the analysis of its cortical effects is ongoing. Investigate this correlation of neuroscience rehabilitation treatments, it is advantageous to have a set of robotic devices for limb mobilization which is compatible with the tight electromagnetic constraints they have provided to modern diagnostic tools (for example, magnetic resonance imaging, magnetoencephalography, electroencephalography), (Pittaccio et al., 2015; Viscuso and Pittaccio, 2012).

Martensitic transformations in shape-effect crystals under the effect of external forces lead to large deformations of an inelastic nature. In some materials, these reversible deformations are in the range from one digit to at least two digits. The recovery of accumulated inelastic deformation and, as a consequence, the return to the original shape of the body can occur both in the process of unloading at a constant temperature (superelastic effect) and in heating (a form memory effect). Both effects are exciting with regard to their application in compact servomotors when heating the effect of shape memory generates stresses in most materials. If the shape memory alloy faces any shape recovery resistance, it can generate reactive force. The importance of this effect in technical applications is that the reactive force significantly exceeds the force that caused the initial change of shape. This can be used to produce a useful mechanical work (Priadko et al., 2017).

Studies on a single crystal Al-5.0\% by weight Al$5.0 \%$ by weight $\mathrm{Ni}$-fused from the melt downstream $<100>$ by the Stepanov (Nikolaev et al., 2008) method in the form of cylindrical rods with a diameter of $5 \mathrm{~mm}$ with the samples heat treated, extinguished at $900^{\circ} \mathrm{C}$ in water followed by soft tempering at $373 \mathrm{~K}$ for 1 hour (According to differential scanning calorimetry, the following non-loadable transformation temperatures are: $M_{s}=52^{\circ} \mathrm{C}, M_{f}=39^{\circ} \mathrm{C}, A_{s}=49^{\circ} \mathrm{C}, A_{f}=60^{\circ} \mathrm{C}$ ), shows crystal transformation temperatures from the applied stress in traction load thermal cyclic experimentation.

Figure 1 shows transformation temperatures for the crystals versus applied stress in thermocycling experiments under tensile load. 


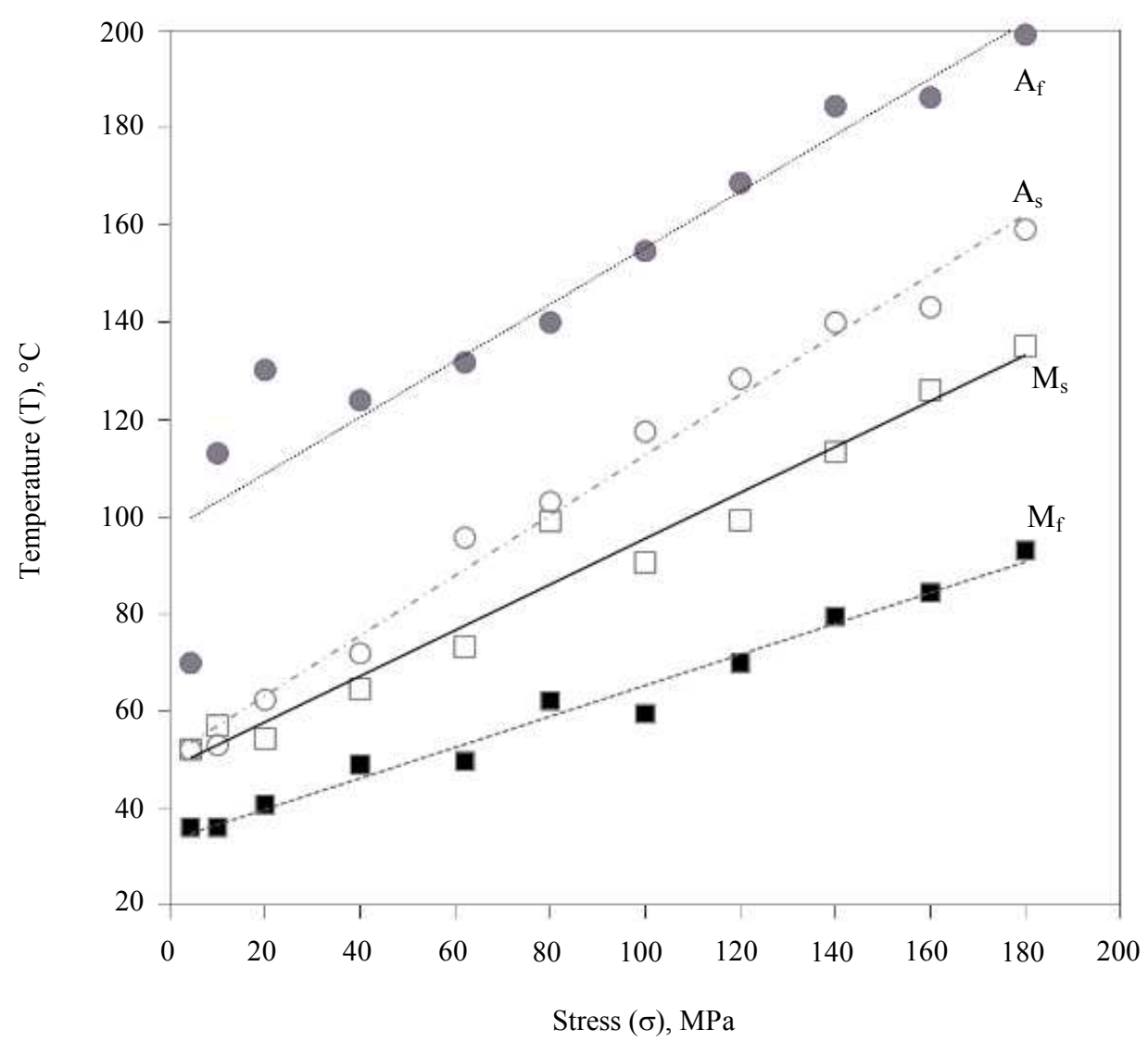

Fig. 1: Transformation temperature for $\mathrm{Cu}-13.5 \% \mathrm{Al}-5.0 \% \mathrm{Ni}$ single crystals versus stress in thermocycling experiments under tensile load (Priadko et al., 2017)

To determine the reversible and residual deformations, as well as the dependence of the transformation temperatures on the applied voltage, thermal cycles were performed under load conditions. Stress $\sigma$ was applied to the test sample at a temperature of $20-30^{\circ}$ above the temperature at the end of the inverse martensitic transformation $\Delta \varphi(\sigma)$ and then cooling-heating cycle under load. Intense sample deformation began in semicircular cooling when direct direct conversion $M_{s}(\sigma)$ was reached and was stopped at the final temperature of direct martensitic transformation $M_{f}(\sigma)$.

Then, in the semi-heating cycle, when the temperature reached the onset of inverse transformation of $A_{s}(\sigma)$, an intensive form recovery ended, ending at the final temperature of the inverse transformation $\Delta f(\sigma)$.

Thus, a thermal load curve corresponding to a given load was recorded, after which the applied voltage was increased and the thermal cycle was repeated. In the voltage range up to $180 \mathrm{MPa}$ and temperature up to $200^{\circ} \mathrm{C}$, there are no deformations and deformations of the shape memory crystals accumulated during cooling, being completely restored to heating.
Figure 2 shows the reversible deformation of the shape memory $\varepsilon_{S M}$ versus the stress $\sigma$ acting in the thermal cycle. The maximum deformation of the SM $\left(\varepsilon_{S M}=8,4 \%\right)$ is achieved when applying stress of at least $62 \mathrm{MPa}$. When the sample is clamped so that the recovery of remembered shape is restricted, the stresses generated upon heating amount to $\sigma_{\text {gen }}=180 \mathrm{MPa}$. The difference in stresses makes it possible to design a device that produces useful work.

The research presented aims to show that optimized Systems based on Memory Alloy forms (SMAs) can be designed using muscles that function as a biomimetic model. In particular, skeletal muscle pairs and pairs of antagonists have been used as a biomechanical model, are voluntary muscles that allow the body to move and represent $40 \%$ of body weight (Lindstedt, 2016).

Skeletal muscles are held by bones by tendons, which are designed to transfer the force generated by muscle contraction to the bone.

The tendons are made of robust tissue and work as special viscoelastic connectors between the bone and the muscles. 


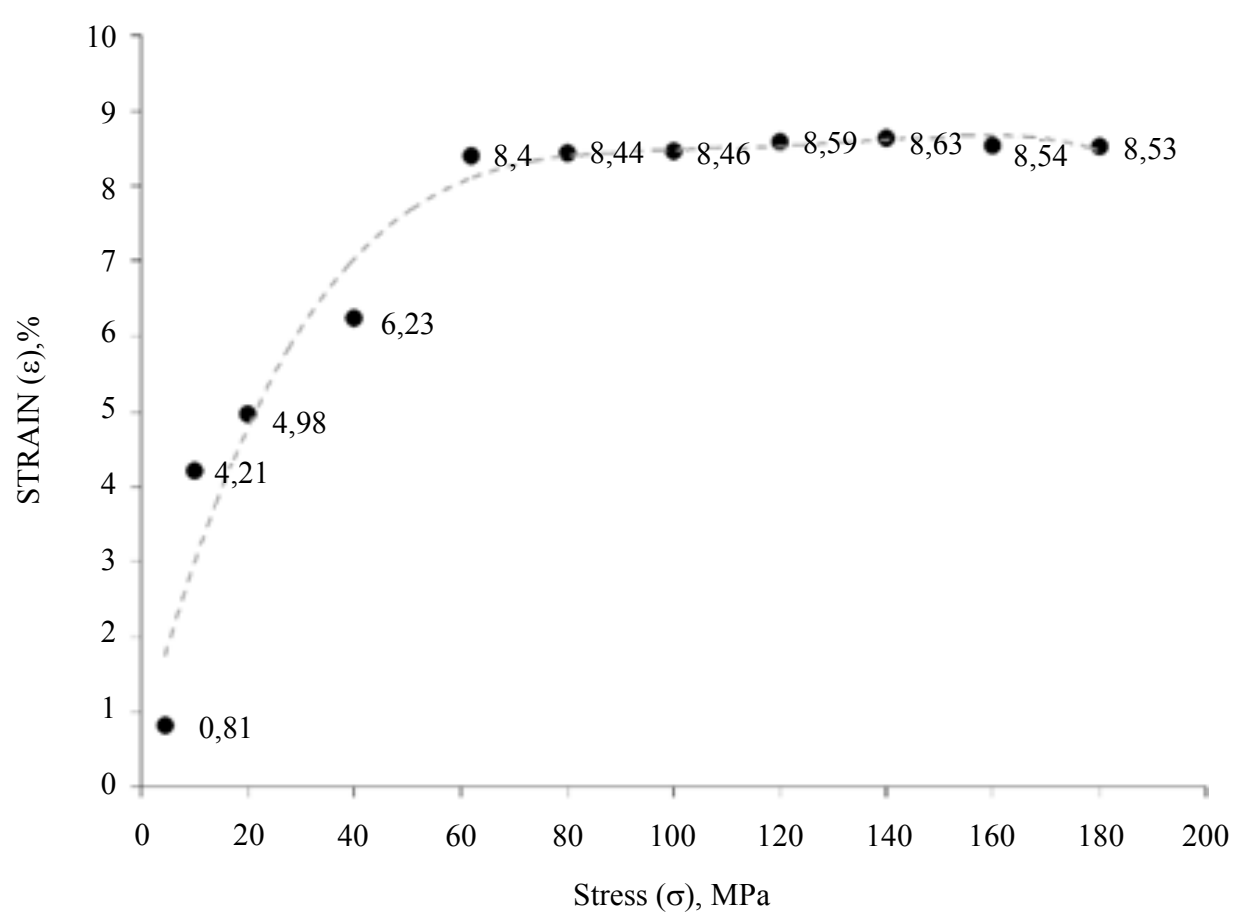

Fig. 2: Reversible shape memory strain $\left(\varepsilon_{S M}\right)$ versus stress in $\mathrm{Cu}-13.5 \% \mathrm{Al}-5.0 \% \mathrm{Ni}$ crystals in thermo-cycling experiments under tensile load (Priadko et al., 2017)

For an adduction motion in a joint, shrinkage and shortening of the muscle generates a force that is applied to a lever system that causes joint adduction movements. In order to recover their initial position, the mutual muscles on the other side of the joint contracts and to shorten.

As described by Biewener and Roberts (2000), the muscles are typically coupled in opposition so that the movements of the joints are driven by a mechanism in which a group of muscles contracts while another group relaxes or prolongs.

In principle, the antagonist pairs are muscles in which the bone moves in one direction and the other moves in reverse, in a transmission of nerve impulses to the muscles. In the arm of the human arm, the biceps of the agonist shorten and bend the forearm from the joint, instead, on the movement of the luggage; the antagonist triceps shortens and restores the forearm to the initial position.

In general, the muscle applying the force required for movement is only one of the antagonist-antagonist pairs and in particular there is always a selectively stimulated stimulation of the brain acting on the muscle or the muscle contraction agonist while the reciprocal behavior is passive, works approximately as a break (antagonist). The active musculature for a certain movement is always the one that contracts (Yang et al., 2013).

A unique class of intelligent materials that have in common with the muscles the ability to react once (the heat in this case) with a change of shape and therefore a downward movement, if necessary, is that of Shape Memory Van Humbeeck, 2010).

This analogy between muscle contraction and the degree and capacity of this class of intermetallic alloys to undergo contraction and extension (superheating) under the effect of thermal and mechanical stimulation allows us to derive a biomechanical inspired machine based on these materials.

The US Naval Ordnance Laboratory first discovered the Effect Memory (memory form) in 1960. The researcher discovered this effect in a nickel and titanium alloy from 1 to 1 , but only today, a greater spread for the biomedical field, actuators, couplings and surgical instruments.

However, SMA industrial or product applications are still so poorly used and potential SMAs are rarely and poorly exploited.

Nickel-titanium alloys are intermetallic compounds (Otsuka and Ren, 1999) and are able to show the effect of thermal memory, namely return to initial heating even when it deforms to a great extent (up to $10 \%$ ).

The displacement-displacement-temperature diagram of Fig. 3 resumes the thermo-mechanical behavior of these NiTi-based materials.

An NiTi alloy involves, at high temperatures, a simple, cube-centered structure known as austenite.

When purchased at lower temperatures (treatment A in Fig. 3 and 4), this solid, solid, intermetallic solid alloy turns into a more complex tetragonal crystalline structure, identified as martensite. 
Thermomechanical behaviour of SMA

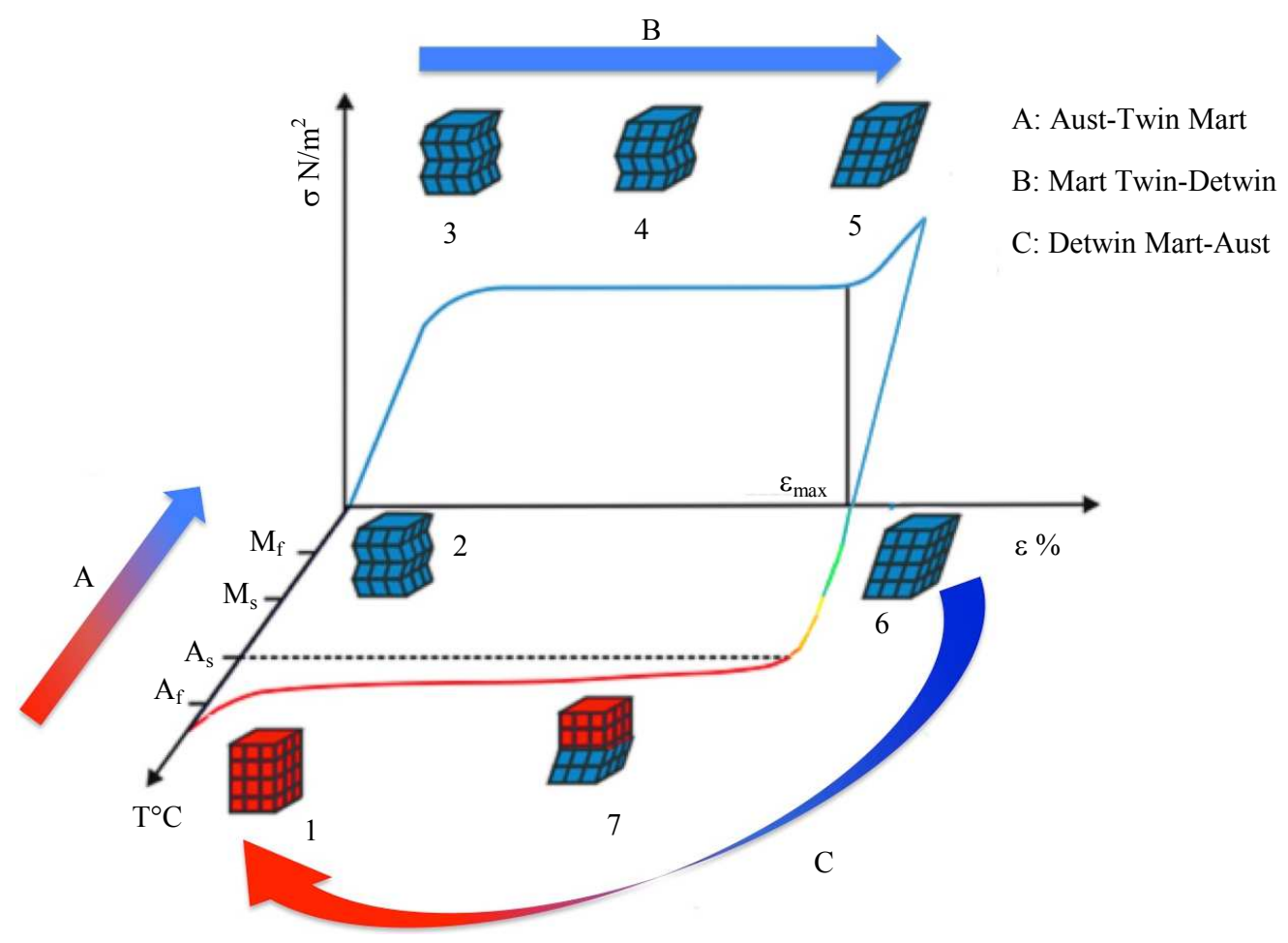

Fig. 3: SST diagram of thermal and mechanical induced transition in Shape Memory Alloys

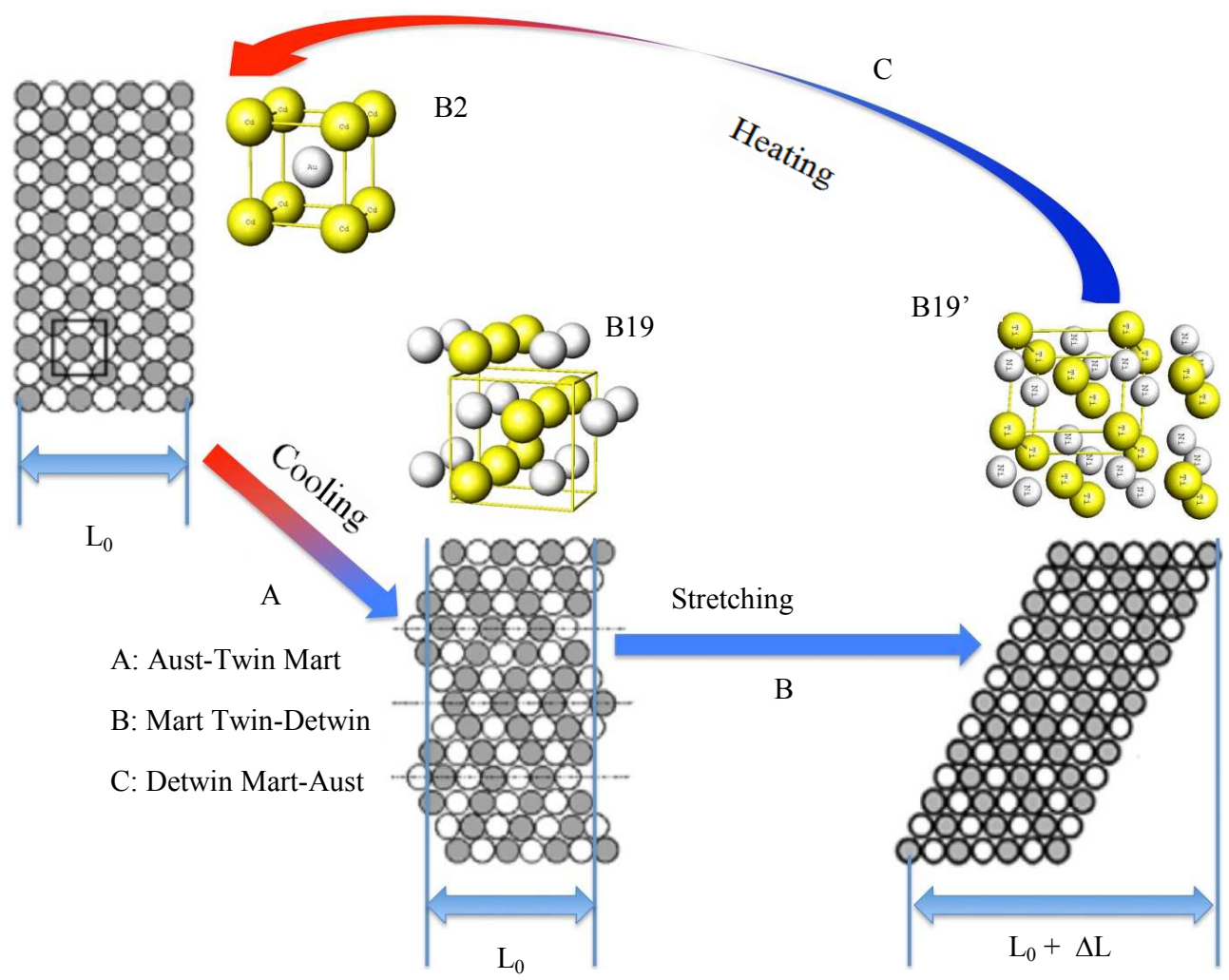

Fig. 4: BThermal and mechanical induced transition in Shape Memory Alloys 
The crystalline structure (CCA) of the austenitic body has a possible crystallographic type that can be obtained at steady state (high temperature 1 in Fig. 3), which is identified as type B2 (Fig. 4).

After cooling, the austenite crystals suffer a transformation of the non-diffusive solids to the metastable martensitic.

According to Otsuka and Ren (1999), it was recognized that the TiNi binary transformation results from the BCC mother structure (type B2 in Fig. 4) at the edge of the FCC.

Austenitic (B2) on the body can be transformed into a local shear mechanism without diffusion in orthobombular or martensitic phases. Marginal later is a B19 monoclinic phase (Otsuka et al., 1971; Knowles and Smith, 1981; Miyazaki et al., 1984; Matsumoto et al., 1987), which was justified as a monoclinic modification of orthogonal B19 (see Fig. 4).

The transition between these structures requires little thermal activation because it involves transformation without diffusion and leads to a rapid rearrangement and rearrangement of atomic positions.

For this crystalline conformation, however, there are two different crystallographic variants with small energy differences. These two configurations consist of rearranging the crystalline atomic planes (sections 2 and 6 of Fig. 3) that were incorporated (B19 in Fig. 4) and were deformed (B19 "in Fig. 4).

Martenita is described as a crystallographic inversion, which means that a given plate is subjected to a reverse inverse heating shear.

Normally, martenita is only formed by cooling, only under Ms, but can also occur at higher temperatures than $\mathrm{M}_{\mathrm{s}}$ if a stress is applied (Yang and Wayman, 1999).

Martenita formed under these conditions is called Stress-Induced Martensite (SIM).

It can be deduced that the predominant driving force for martensitic transformation above $M_{s}$ is not thermal but mechanical (transformations B in Fig. 3 and 4). Above the temperature at which martensitic transformation starts $\left(M_{s}\right)$, the stress required for SIM production increases progressively with temperature rise (Šittner et al., 2014).

Linear variation of stress for induction of martensite by temperature was experimentally observed and may also be derived from a thermodynamic approach. The thermodynamics governing relationships between physical property variations (volume, temperature, pressure) is subject to the Clausius-Clayperon equation and is written as:

$$
\frac{d P}{d T}=\frac{\Delta H}{T \cdot \Delta V}
$$

where, $P$ is the pressure, $T$ is the temperature and $\Delta H$ is the latent heat of phase change (that can be determined by DSC analysis) and $\Delta V$ is the volume change of the phase change (the volume change for NiTi Austenitic to Martensitic phases may be calculated from the dimension of the crystalline units, namely a cube of $0.3015 \mathrm{~nm}$ for Austenite to the $0.4622 \times 0.4120 \times 0.3015$ $\mathrm{nm}$ for the Martenisite (orthotrombic or nonoclinic).

Equation 1 that may result more convenient in chemical physical and chemical fields but for mechanical aspects it may be substituted by a Clausius-Clayperon derivation (Duerig, 1990) that assumes the form:

$$
\frac{d \sigma}{d M_{s}}=-\frac{\Delta H}{T \cdot \varepsilon_{0}}
$$

where, $\Delta H$ and $T$ have the same interpretation as for Equation 2 and $\sigma, M_{s}$ and $\varepsilon_{0}$ are the applied stress, the shifted $M_{s}$ temperature and the transformational strain resolved along the direction of the applied stress.

Moreover, it was theoretically predicted (Clasius Claypeiron 2) and experimentally determined (Šittner et al., 2014) that the level of mechanical loading required to create Stress-Induced Martensite (SIM) increases linearly with temperature. These reverse phase transformations are known as martensitic transformations requiring mechanical loads of between 70 and $140 \mathrm{MPa}$ (Duerig, 1990), depending on the temperature.

According to equation 2, the voltage drops to zero from the lady.

Stress caused by martensite continues to rise to a temperature up to $M_{d}$, beyond which the critical stress required to induce martensite is greater than the required displacement voltage (not for reversible plastic deformation).

Therefore, the temperature range for the SIM is from $M_{s}$ to $M_{d}$. For a number of SMA systems, the stress-dependent temperature agreement to form the SIM according to the Clausius-Clayperon equation is quite striking.

The equation works equally well for the nonisothermal case, i.e., if the temperature has been kept constant, while the force required for martensite formation has been measured.

Super-elasticity occurs when a material is deformed above $A_{s}$ but still under $M_{d}$. In this area, martensite can be stabilized by applying stress but becomes unstable after stress release.

By mechanical stretching (treatment B of Fig. 3 and 4), the SMA is deformed to a greater extent (states 3-4 in Fig. 3 and structures B19 and B19 'in Fig. 4). This pseudo-plastic deformation is possible by reorienting crystallographic variations to cold temperature after twinned martensite transformations (B19). Consequently, deformation persists after load removal (from state 2 to 3 in Fig. 3). Upon reheating, process C of Fig. 3 and 4, the material gradually turns into the austenite crystalline 
network B2 (from state 6 to intermediate state 7 and final state 1 in Fig. 3) recovering its initial form.

During the recovery of this form, strong forces and high forces are generated, which have a particular benefit for the development of temperature-activated servomotors.

As shown on the temperature axis in Fig. 3, the four characteristic temperatures of SMA are Mf (Martensite Finishing), Ms (Martensite Cooling) and As (Austenite Start) and Af (Austenite Finishing).

When the SMA is heated, it begins to turn into austenitic phase at $A_{s}$ and terminates the transition to temperature $A_{f}$; Similarly, on cooling, transformation into Martenita starts from the temperature and ends the transition to $M_{f}$ temperature.

However, for some $\mathrm{Ni} \mathrm{Ti}$ alloys, an intermediate phase, called R-phase $R$, may be shown, in which case the characteristic temperatures are indicated as $R_{s}$ and $R_{f}$. This event is manifested by thermal events that can be measured in differential scanning calorimetry. The calorimetric analysis was performed on our samples to identify not only the typical austenitic martensitic temperatures but also the aspect of the intermediate rhombic sides.

SMAs can show two types of Memory Effects (IMEs), defined as unique and bidirectional effects. For a unique effect, it is meant the ability of SMA to retain and resume the macroscopic form associated with the austenite phase when heated to A2; for the bidirectional effect, it is understood that the first skill described has added the ability to recover and the macroscopic form associated with the martensitic phase when cooled to the Mf temperature.

To obtain a one or two memory effect, thermomechanical treatments (Naresh et al., 2016) are required to program predefined forms for the martensitic and austenitic phases.

The basic idea of this paper on how and why to use the biomechanical model of working muscles is discussed in the following paragraphs.

\section{Materials and Methods}

\section{Materials}

To experiment and develop the biomimetic model for optimizing SMA-based systems, Dinalloy Inc.

Flexinol is an SMA with nickel and titanium as the main chemical components.

\section{Devices and Procedures}

\section{Differential Scanning Calorimetry (DSC):}

Thermocalorimetric analyzes were performed on NiTi alloys. DSC technology determines the temperature and heat flux associated with material transitions according to time and temperature. It also provides quantitative data on endothermic processes (heat absorption) and exothermic (heat evolution) of materials during physical transitions (Ziólkowski 2012; Shaw et al., 2008).

The thermo-calorimetric characterization was performed in a nitrogen atmosphere by a Mettler ADSC differential scanning calorimeter equipped with a liquid nitrogen cooling unit in the temperature range from -30 to $120^{\circ} \mathrm{C}$.

The temperature scenarios were performed at $5^{\circ} \mathrm{C} / \mathrm{min}$. For sample stabilization an isothermal scan was performed at $500^{\circ} \mathrm{C}$, the heat flux was recorded at the apparent balance (heat flux $=0$ ).

High-temperature treatment induces crystalline structure atoms to rearrange the most compact and regular pattern, resulting in a rigid cubic austenitic phase (Kauffman and Mayo 1993; Yang et al., 2013). Figure 5 shows a typical DSC thermogram performed on a Flexinol yarn sample $(0.25 \mathrm{~mm}$ diameter, $4.00 \mathrm{mg})$.

\section{Results}

One has performed the SMA alloy of our activity dynamic tests consisting of a heating segment from -30 to $120^{\circ} \mathrm{C}$ and a cooling segment from 120 to $-30^{\circ} \mathrm{C}$ and at a rate of temperature change of $10^{\circ} \mathrm{C}$ minutes, reported tests in Fig. 5. Thermal analysis was performed following an isothermal treatment at $500^{\circ} \mathrm{C}$, used to simulate the required annealing state for SMA training, in order to "memorize" its austenite form. This step is very important for SMA vendors to only give information about the characteristic alloy temperature before training, but obviously the transition temperature range changes after the thermal treatment used for SMA programming (Kus and Breczko, 2010). For the thermal analysis, an ADSC Mettler Toledo was used. The DSC routes in Fig. 5 report thermal (underneath) and cooling (upper) thermograms relative to the investigated SMA. As already mentioned, all of the SMA samples were heat treated for 10 minutes at $500^{\circ} \mathrm{C}$ in order to stabilize the austenitic phase.

It can be seen from Fig. 5 that the first heating cycle at $10^{\circ} \mathrm{C} / \mathrm{min}$ has an endothermic peak belonging to the martensitic-austenitic transition (Fig. 5). Then, the transformation of the martensite orthorhombic phase (B19) into the austenitic phase based on the cubic body (B2) begins at $49^{\circ} \mathrm{C}$ and ends at $60^{\circ} \mathrm{C}$ (to follow the dotted lines in Fig. 5). It can be seen that the cooling part of the thermal cycle presents a more complex thermal behavior. Thus two peaks were observed on cooling.

At this point it should be mentioned that monoclinic martensite B19 can be obtained either by a single phase shift of phase B2 $\rightarrow$ B19 (single peak in DSC) or by a twophase phase shift of phase B2 $\rightarrow \mathrm{R} \rightarrow \mathrm{B} 19$ "(Otsuka and Ren, 1999, Otsuka et al., 1976; Yang and Wayman, 1992; plus two peaks may be evident on a DSC 
thermogram. We further specify that in the two-stage transformation, the $R$ phase is an intermediate Roman phase which is not compatible with the final cubic austenitic phase B2. The lattice parameters of phase B2, phase R and phase B19 and the correlations between the transitions of the sides between phase B2 and R and B2 to B19 have been well established (Otsuka et al., 1971; Knowles and Smith, 1981; Matsumoto et al., 1987; Yang and Wayman, 1992).

The transformations produced in two phases of the phase $\mathrm{B} 2 \rightarrow \mathrm{R}$ and the phase $\mathrm{R} \rightarrow \mathrm{B} 19$ can then occur on cooling when $R_{0}$ (initial temperature $\mathrm{B} 2 \rightarrow$ phase transition R) is over $M_{s}$ (Otsuka and Ren, 1999). This phenomenon could also be observed in stress-induced transformations (Otsuka et al., 1976). Differential thermal treatments as well as the resistance to visible voltages in Fig. 4 characterize the transitions induced by two temperatures and voltages induced in a $\mathrm{Ni} \mathrm{Ti}$ alloy.
Figure 6 shows a detailed detail of the DSC thermograms relative to this transition in two stages observable on the refrigeration thermogram.

Immediately after cooling the parental phase B2 is first transferred to the rhomboidal phase (R phase) and then to $R_{s}$ from phase $R$ to the martensitic phase to $M_{s}$, so that eventually the martensitic transformation in phase $\mathrm{R}$ stops at $M_{f}$. The inverse transformation will take place from martensitic phase to parent phase B2 to $A_{s}$ and is considered finished at $A_{f}$. (at a temperature close to $-10^{\circ} \mathrm{C}$ ). Figure 6 (top) also shows an experimental curve related to the temperature dependence of the Ms state of martensite on the Ni-Ti relative composition given either in the nickel content (see left axis) or in the $\mathrm{Ni}$-Ti ratio (visible on the axis right) derived from the data of Harrison and Hodgson (1975; Hanlon et al., 1967).

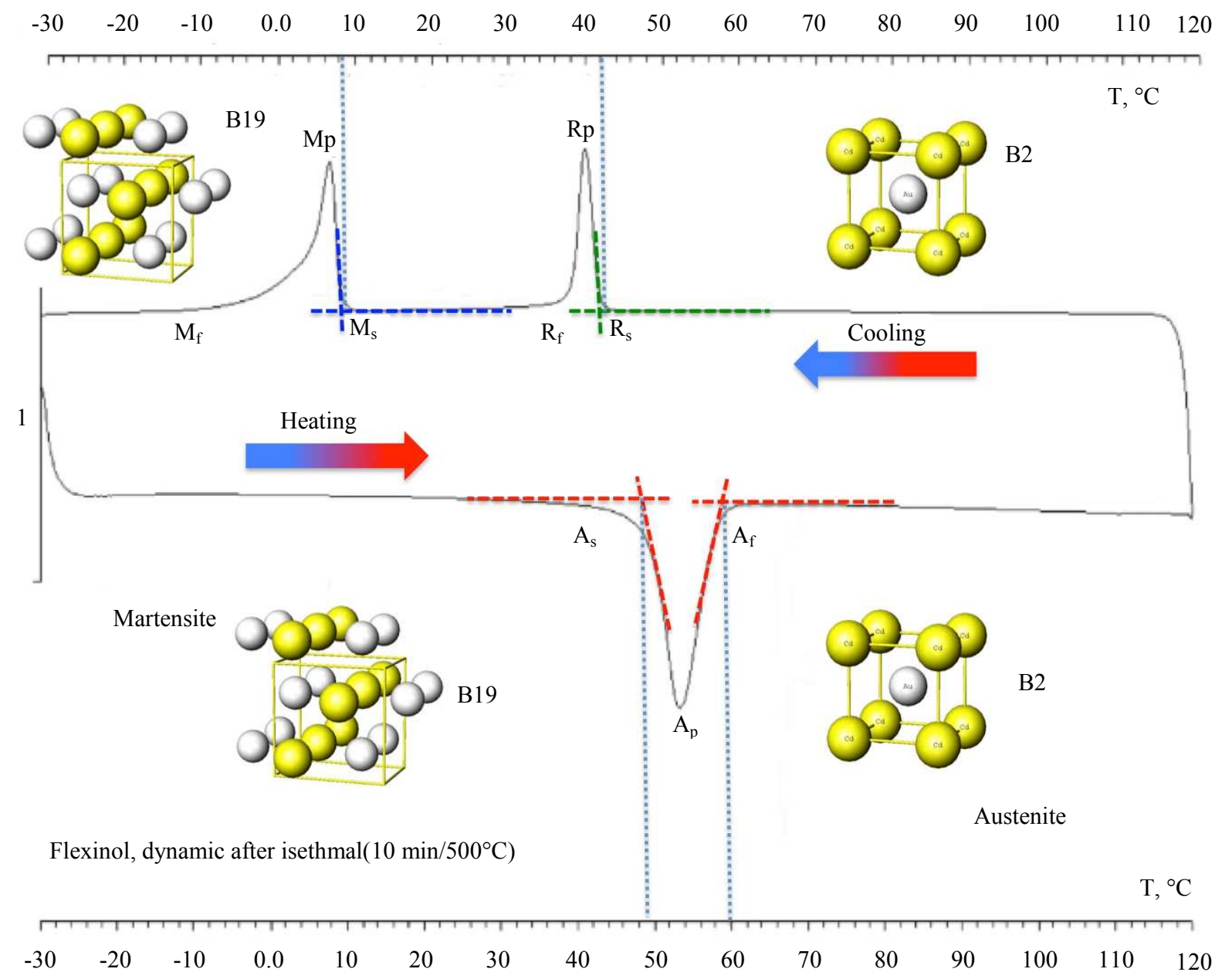

Fig. 5: DSC analysis performed for a specimen of Flexinol wire. Heating segment from $-30^{\circ} \mathrm{C}$ to $120^{\circ} \mathrm{C}$, cooling segment from $120^{\circ} \mathrm{C}$ to $-30^{\circ} \mathrm{C}$. Heating and cooling rates $10^{\circ} \mathrm{C} / \mathrm{min}$ 


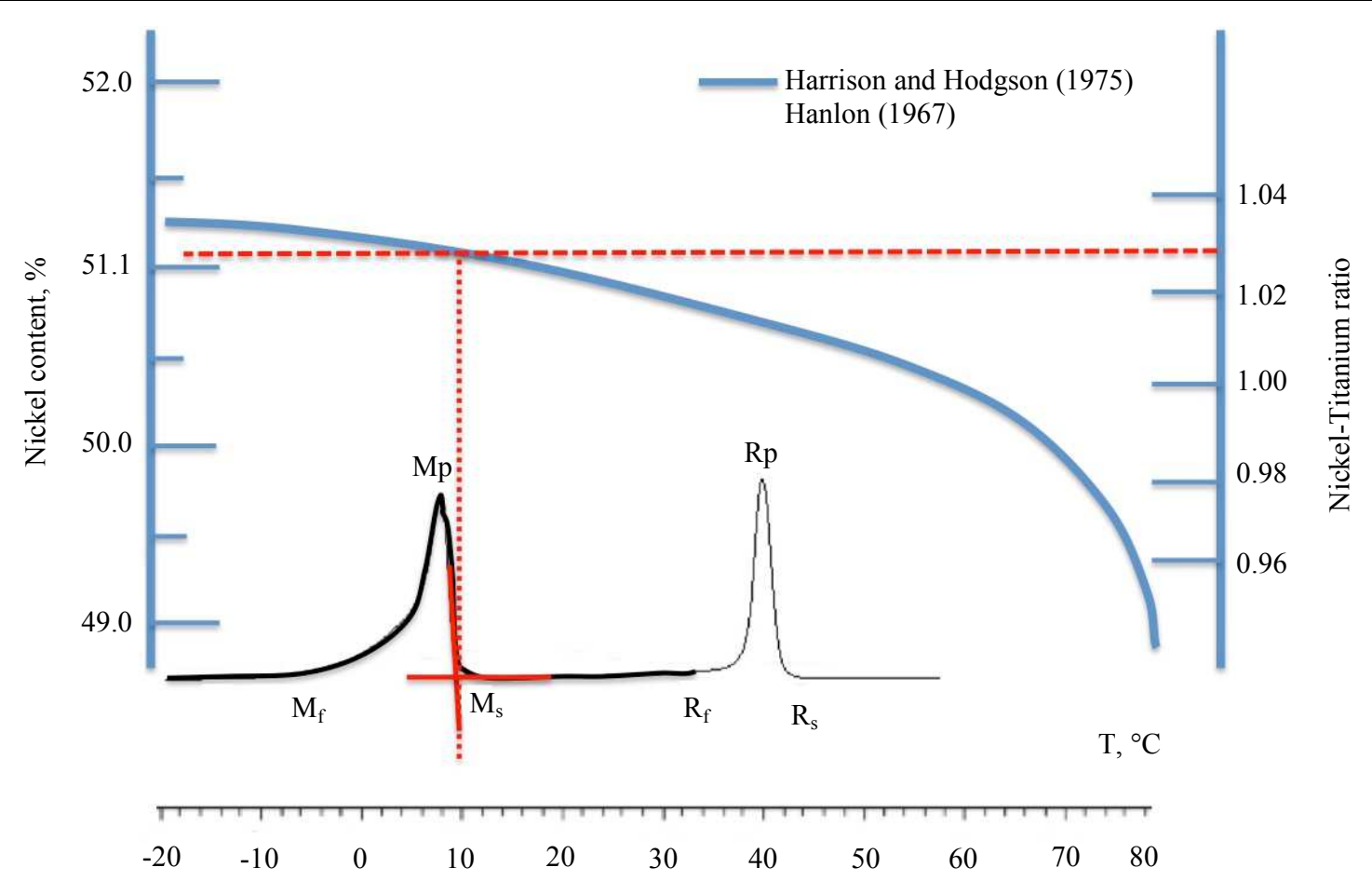

Fig. 6: Detail of DSC characterization of the NiTi alloy composition in the cooling stage

Experimentally, from our thermal characteristic, a composition of $51 \% \mathrm{Ni}(1.03 \mathrm{Ni}-\mathrm{Ti}$ ratio) (represented by the red dotted line in Fig. 6) was observed.

Huang et al. (2003) gave a physical explanation that eliminated the need for two different mechanisms to describe the effect of two-way memory. They found that the structure B19 "NiTi is not stable in the orthorhombic structure and cannot be stored in atomic memory. However, this structure has been described to be stabilized by a wide range of internal and applied residual voltages and that the memory is stored primarily at the microstructural level. The use of the muscle function model also depends on the need to optimize SMA-based systems from the point of view of their energy needs and not just their ability to change shape.

Due to the relatively low martensite transition temperatures $\left(M_{f},-10^{\circ} \mathrm{C}\right)$, to use and program the SMA for a bidirectional memory effect in an industrial application, the machine must be equipped with a cooling system to make the martensitic passage on the other heating system to obtain and maintain the austenitic crystalline phase. The developed system type is based on the use of trained SMA wires to have a unique sense of IMM to "remember" only the preset shape associated with the austenitic phase. Movements and therefore shape changes depend only on the forces generated by the yarn contraction, such as the mechanism of the existing pairs of muscle antagonists.
In principle, the system is made up of articulated joints and a lever mechanism assembled on the SMA wires. When the wire (SMA Blue Line in Fig. 7) shortens, pulls and causes the shape to change through the hinge joints and the lever mechanism. In order to bring the system back to the initial position (abduction), the "reciprocal" wires on the sides of the joints have to contract and shorten.

As if you work in the blood, when the middle thread contracts, the other stretches and is in the opposite direction. The wire contraction can be selectively activated by a passage of an electric current which causes an increase in the wire temperature (due to its electrical resistance and hence its heating) Sofla et al., 2008). A schematic representation of the biomechanically inspired machine is shown in Fig. 8.

The solution is mechanical and accessible in relation to the forces generated by the thread. In fact, the characteristic mechanical properties of SMA depend on the crystalline phase and, therefore, at different temperatures, the mechanical behavior is different.

In particular, the Young module of the austenitic phase may be several times greater than that of the martensitic phase. This is why SMAs are easier to apply at low temperatures (martensitic temperature range) than at high temperatures (austenitic temperature range). But the forces generated will be greater than those for martensitic phase B19, due to the different Young's modulus during the heat induction induced by the austenitic B2associated form (Melton and Mercier, 1980). 

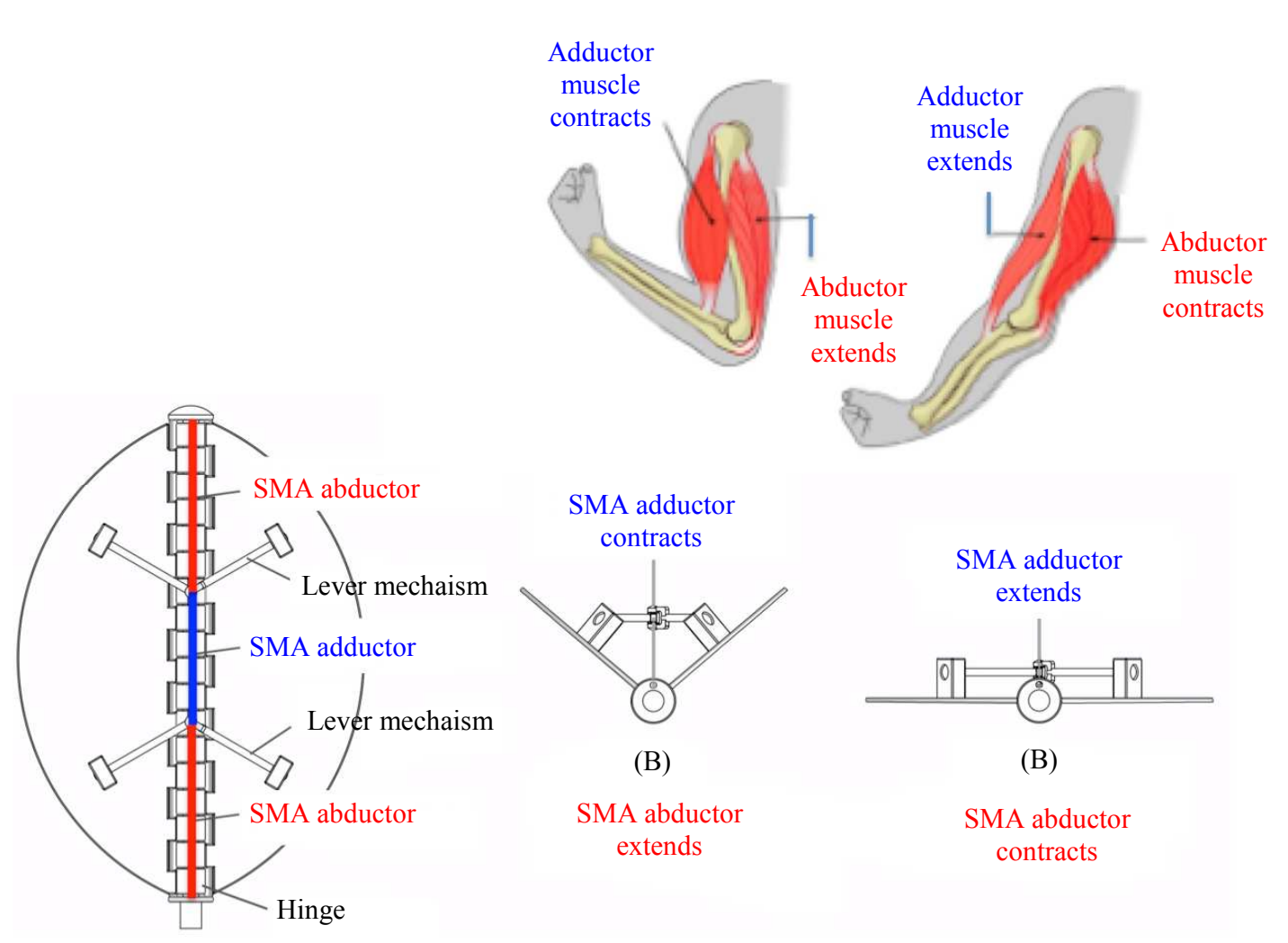

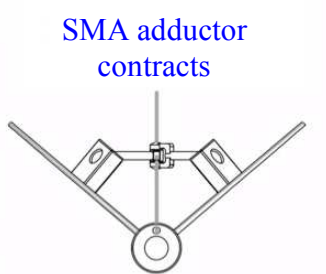

(B)

SMA abductor extends

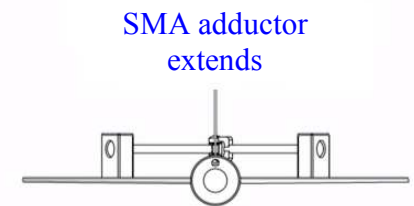

(B)

SMA abductor contracts

Fig. 7: Biomechanically inspired SMA driven machine

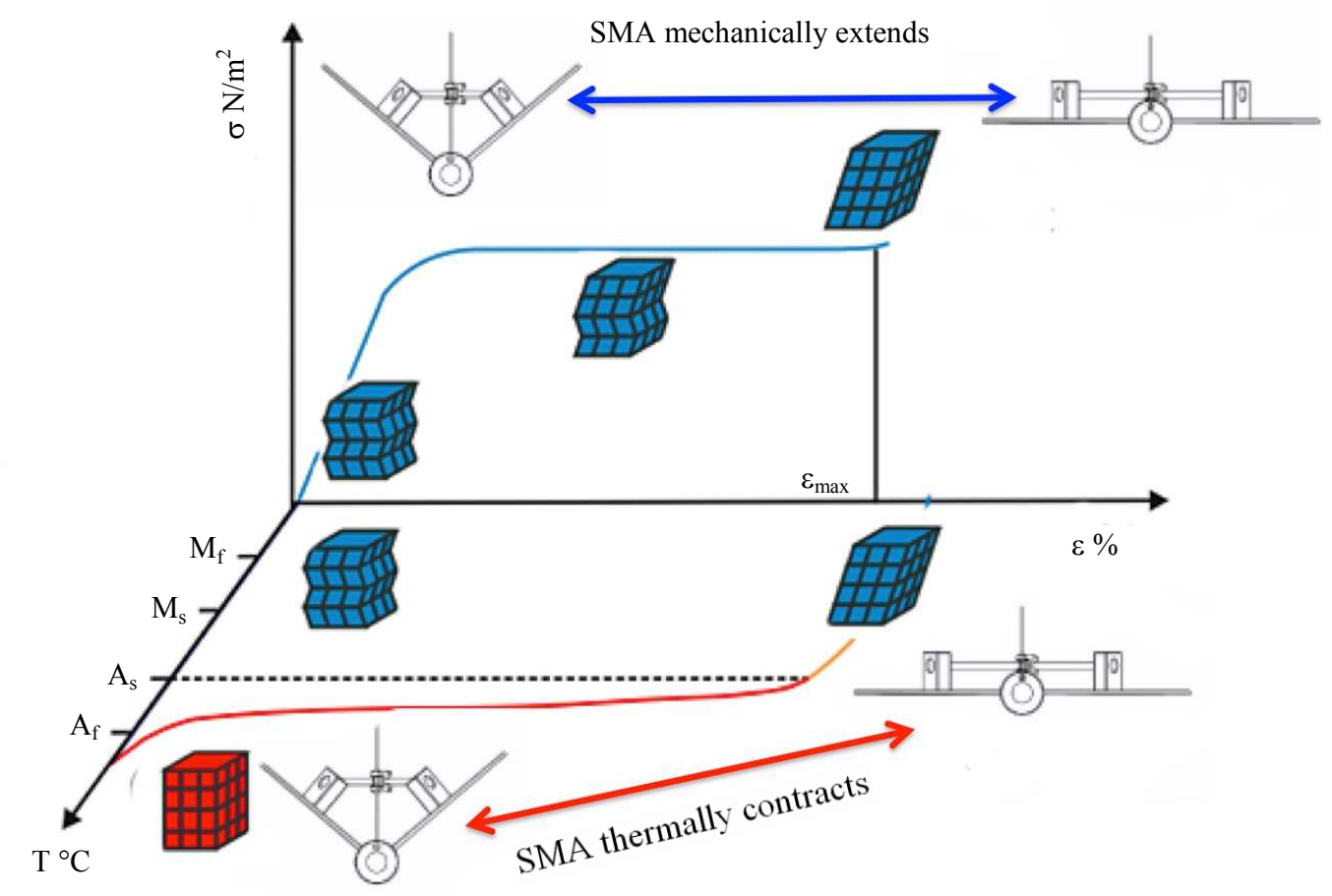

Fig. 8: C Thermo-mechanical transformations of SMA adductor and abductor of the biomechanically inspired machine 
In the $0.51 \mathrm{~mm}$ NiTi alloy conductor, the power generated for Martensite B19 transformation into Austenite B2 is nearly 250\% higher than B19 martensite B19 "detwinned" (Dynalloy datasheet).

That is, the firing torque (lower part of Fig. 8) is $34.92 \mathrm{~N}$ and after being cooled by the subformed martensitic force B19 to B19 'is $13.96 \mathrm{~N}$ (Fig. 8).

\section{Discussion}

This SMA thermo-mechanical effect can be used to mimic biomechanical behavior of the agonist and muscle antagonist to accurately drive a bio-inspired machine. As shown in Fig. 8, NiTi thermo-mechanical alloys and the bio-inspired machine of Fig. 7, the SMA heatreduction agonist associated with the transformation of martensite B19 into austenitic B2 produces adhesion from the two arms of the machine, while the SMA abductor extends from Martensite twinned B19 to Martensite B19 'stretched (Fig. 7).

Expansion of machine arms can be achieved by reversing the heating stretching signal (B in Fig. 7). In this move, the SMA abductor contract previously extended from B19 'detwinned Martensite to B2 Austenite, while the SMA adductor extends from B19 to the martensite B19' detwinned.

A system that exploits the above-mentioned mechanism can generally be used for industrial applications characterized by intelligent and responsive behavior. The purpose of the presented research is not to design a specific application but to provide a biomimetic model to be used for a wide range of adaptive applications (switchable windows, intelligent shadow systems, parking and urban shelters, etc.). shape changes in response to various external stimuli.

Some advantages of using the biomimetic model of muscle work are discussed in more detail in the following paragraph.

The main advantages of the biomimetic approach described in the previous paragraph are:

- Easier and faster change of shape

- A lower need for energy for system operation

- Lower costs for SMA training

- There is no problem of overheating

In order to better understand the advantages presented, it is important to point out that an SMA trained for a unique effect when heated in a macroscopic form associated with austenite and then cooling, although there is a change of the crystalline phase, preserves the macroscopic form of austenitic if not load is applied). Differently, if the SMA has been trained for a bidirectional effect when it cools, it changes shape by taking the form associated with martensite (Aversa et al., 2018, 2017a; 2017b; 2017c; 2016a; 2016b; 2016c; 2016d; 2016e; 2016f; 2016g; 2016h; 2016i; Mirsayar et al., 2017; Petrescu et al., 2015, 2016a; 2016b; 2016c; Petrescu and Calautit, 2016a; 2016b).

One problem with the bidirectional effect is that it is easy and quick to heat the SMA with electricity, but the cooling time (if the external devices and the corresponding devices are not used) is quite high and depends on room temperature and SMA geometry. Our SMA wire with a diameter of $0.51 \mathrm{~mm}$ and a current of $4 \mathrm{~A}$ lasts for a second to contract (austenitic) but about 17 seconds to cool to $70^{\circ} \mathrm{C}$ (room temperature in static air). Heating and cooling times are strongly dependent on many factors (current, chemical composition, geometry and SMA thickness, room temperature, the presence of cooling systems, etc.). However, it is enough to show the big difference in the time it takes to heat and cool an SMA cable.

The system, which uses only shrinkable threads (pairs of antagonistic mechanisms), offers a faster shape change. Moreover, due to the unique sense of the SME, the thread maintains the macroscopic shape associated with the austenitic phase, when it is cooled, there is no need to maintain a range of austenitic temperatures and therefore it is necessary to use the current for a few seconds. Consequently, the energy requirement for system operation is much lower. Assuming we use, for example, two SMA wires, a sensory effect and the other with a bidirectional effect, with a diameter of $0.51 \mathrm{~mm}$ for one hour a day for one month in the austenitic phase, from $4 \mathrm{~A}$ to the first case for 1 second (day) and second case for 3,600 sec (per day) and we believe that a voltage of $6 \mathrm{~V}$ is applied. Using simple calculations:

$$
\begin{aligned}
& P(W)=I(A) \times V(V) \\
& E(k W h / \text { month })=P(W) \times t(h / \text { day }) / 1000(W / k W) \times 30
\end{aligned}
$$

In the first case, we have an energy consumption $(E)$ of $0.0001 \mathrm{kWh} /$ month and the second of 0.7200 $\mathrm{kWh} /$ month (Dynalloy datasheet).

Moreover, using a one-way effect and avoiding long heating of an SMA cable does not result in overheating. If an SMA is overheated, there is a degradation of its properties (Velázquez and Pissaloux, 2012).

Ultimately, single-effect SMA formation becomes easier and cheaper, in fact, the treatment required to establish the austenitic form is just one step, instead, bidirectional training (IMM or SIM procedures) mechanical treatments that need to be repeated 20-30 times (Lahoz and Puértolas, 2004).

The new technology for operating in "intelligent" or "smart" materials has opened new horizons around the world on robotic drive systems. Materials such as piezoelectric fibrous composites, electrically active polymers and Shape Memory Alloys (SMA) are investigated as promising alternatives for standard servomotor technology. There are studies currently 
focusing on the use of SMAs to build muscle-like servomotors. SMAs are extremely cheap, easy to change and have the advantage of working at low voltages.

Using SMA offers a very interesting alternative to the mechanisms used by conventional actuators. SMA allows a drastic reduction in the size, weight and complexity of robotic systems. In fact, the weight-toweight ratio, long life cycles, negligible volume, noisy detection and operation make it possible to use this technology to build a new class of drive devices. However, high power consumption and reduced bandwidth limit this technology for certain types of applications. This is a challenge that needs to be addressed both in terms of materials and control to overcome these disadvantages. Appropriate control strategies and appropriate mechanical mechanisms have proven to dramatically improve SMA performance, especially with regard to speed and limit cycles.

Due to their limitations, SMA has not paid attention to robotic technology for many years. However, recent studies have demonstrated that by: (a) Finding appropriate application niches, (b) dedicated mechatronic design and (c) ad-hoc control strategies, SMA can be effectively used as an alternative technology to drive robotic systems. A careful design that takes into account the particular characteristics of the material coupled with an appropriate mechanical design plays a significant role in the efficient use of SMAs. Even so, it is clear that SMA (and intelligent materials in general) cannot be considered at this stage as a universal replacement of classical servomotor technology. However, niches of applications that benefit greatly from this technology can be found. Artificial bioinspired systems are such a niche.

Although SMAs are mostly used as servomotors, they have detection capabilities. Despite the fact that most physical parameters of the SMA are closely linked in a non-linear hysteresis manner, the electrical resistance varies linearly with the alloy voltage. Since the strain is kinematically related to the movement of the actuator (either linear or rotational), the electrical resistance and motion produced by the actuator are both linearly connected. This linearity between the variation of resistance and movement is achieved due to the martensite, the fraction being dynamically kinematically coupled and the martensite fraction determines the resistance changes. This problem is an advantage for the development of closed loop position for controllers that control the SMA drive. In fact, most of the stresses involved, the linear control of the SMA position, the electrical resistance measurements of the reaction to estimate the actuation value generated by the actuator. This avoids the inclusion of external position sensors for closing the control loop.

SMAs are used in a variety of applications. Their special properties have generated high expectations in different technologies and industries; can be used for this to generate a movement or to store energy. In addition, their scope covers several sectors, from the use of detachable antennas to various machine sensors, materials for the construction of suspended bridges or antiseismic devices. In general, all applications depend to some extent on the effect of the reaction action of the material and the conditions below that occur in a particular application, making a SMA a functional material (Fig. 9), (Coral et al., 2012).

For example, they are used in many non-invasive surgical devices and in biomedicine, taking advantage of their large strains and their ability to recover when the load is removed. This property allows applications in devices such as stents, tubular prosthetic devices because it restores the flowability of any affected channel by solving a narrowing.

In classical robotic systems, linear actuators have been proposed using SMAs.

Servomotors based on SMA offer the right technology, the muscle mechanisms that resemble the thematic mechanics of muscles in biological systems. For this reason, there have been a number of bio-inspired robots in recent years Smart Actuation and Sensing Systems - Recent advances and future challenges of the SMA muscle.

Aliquot formulas are metallic materials with the ability to "recall" a determination form, even after a severe deformation produced by a thermal stimulus. In the case of metal alloys, the shape memory effect consists of a transition that occurs between two solid phases, one of the low or martensitic temperatures and others with high or austenitic temperatures.

The material is deformed in the martensitic phase and inverts the original dimensions by heating above a critical transition temperature. The terms martensite and austenite refers initially only to steel steps, however, these terms have been extended by reference not only to the material, but also the kind of transformation. Thus, the martensite steel involves a change in volume and shape, while the SMA basically has a length change.

Generally, NiTi (nickel-titanium) SMAs are the most common alloys used. This is in principle as these materials are likely to be used both as sensors and actuators, which makes them suitable for integration into intelligent structures. NiTi SMA-based work on the memory effect of the form, which essentially occurs under the influence of temperature changing the material; ie the temperatures at which the martensitic and austenitic phase transformations begin and end. Figure 9 shows how these microscopic changes occur material level. The phase transition occurs when the material is heated or cooled. In general, there is a certain temperature range for the transition, which is defined primarily by the producer. 


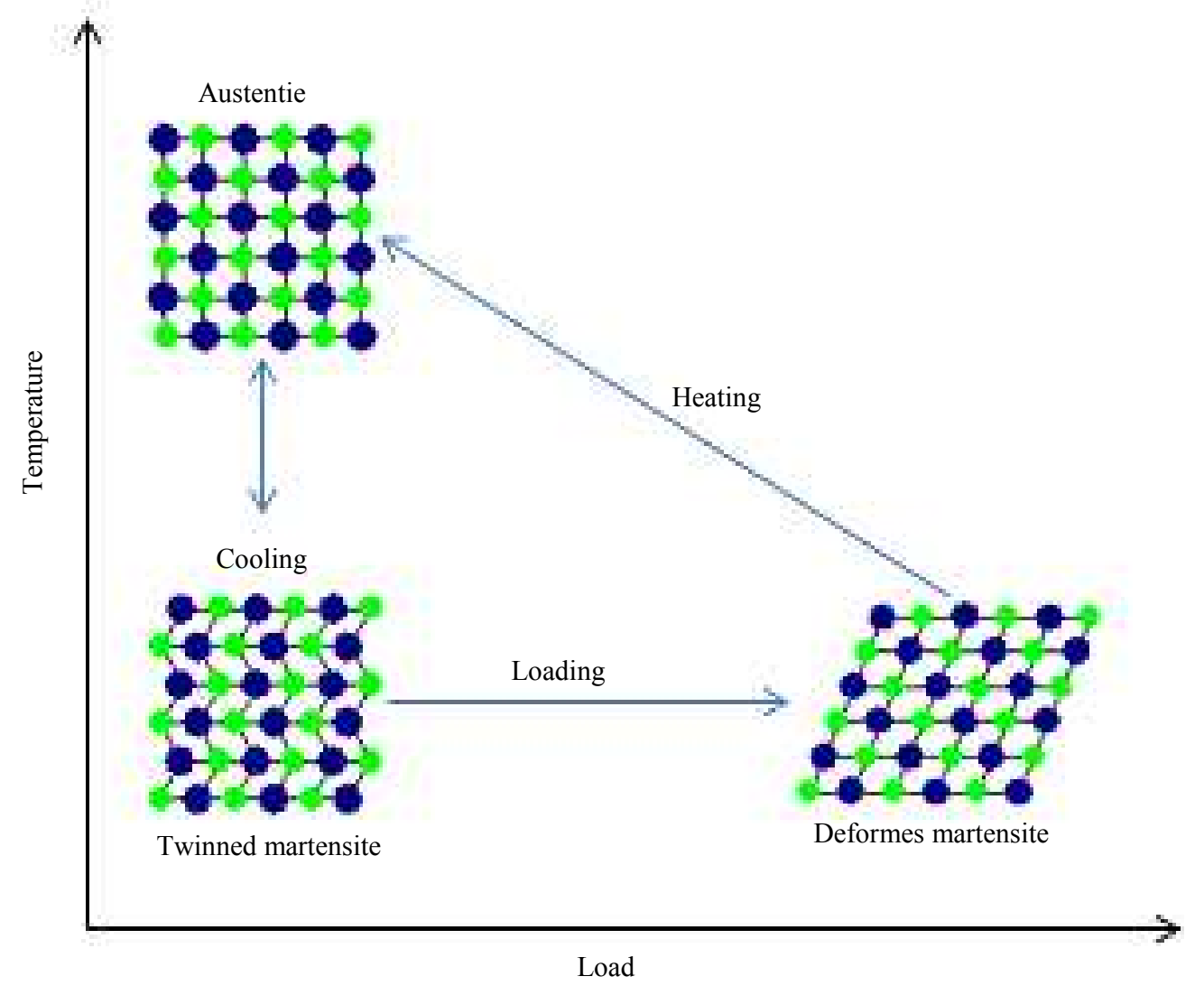

Fig. 9: A microscopic viewpoint of the Shape Memory Effect. Source: (Coral et al., 2012)

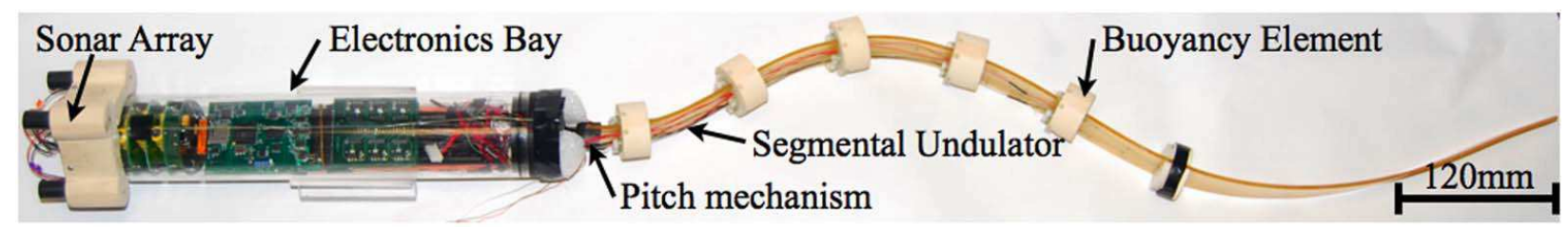

(a)

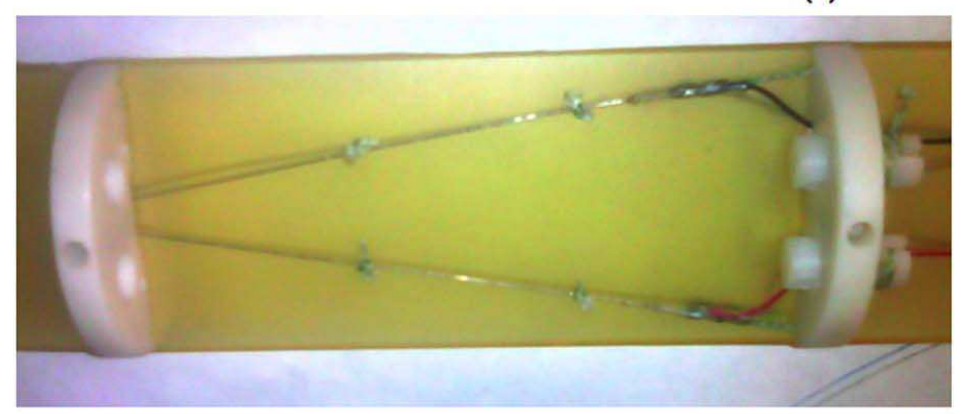

(b)

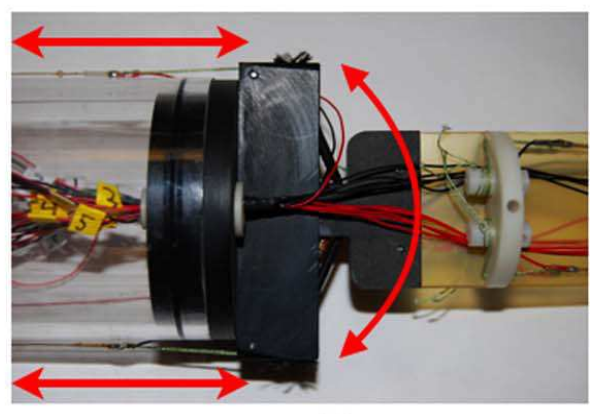

(c)

Fig. 10: Lamprey Robot with sonar array, (b) Lateral view of tail segment showing nitinol actuator, Teflon vertebra and tensioning nuts and (c) Lateral view of pitch mechanism 


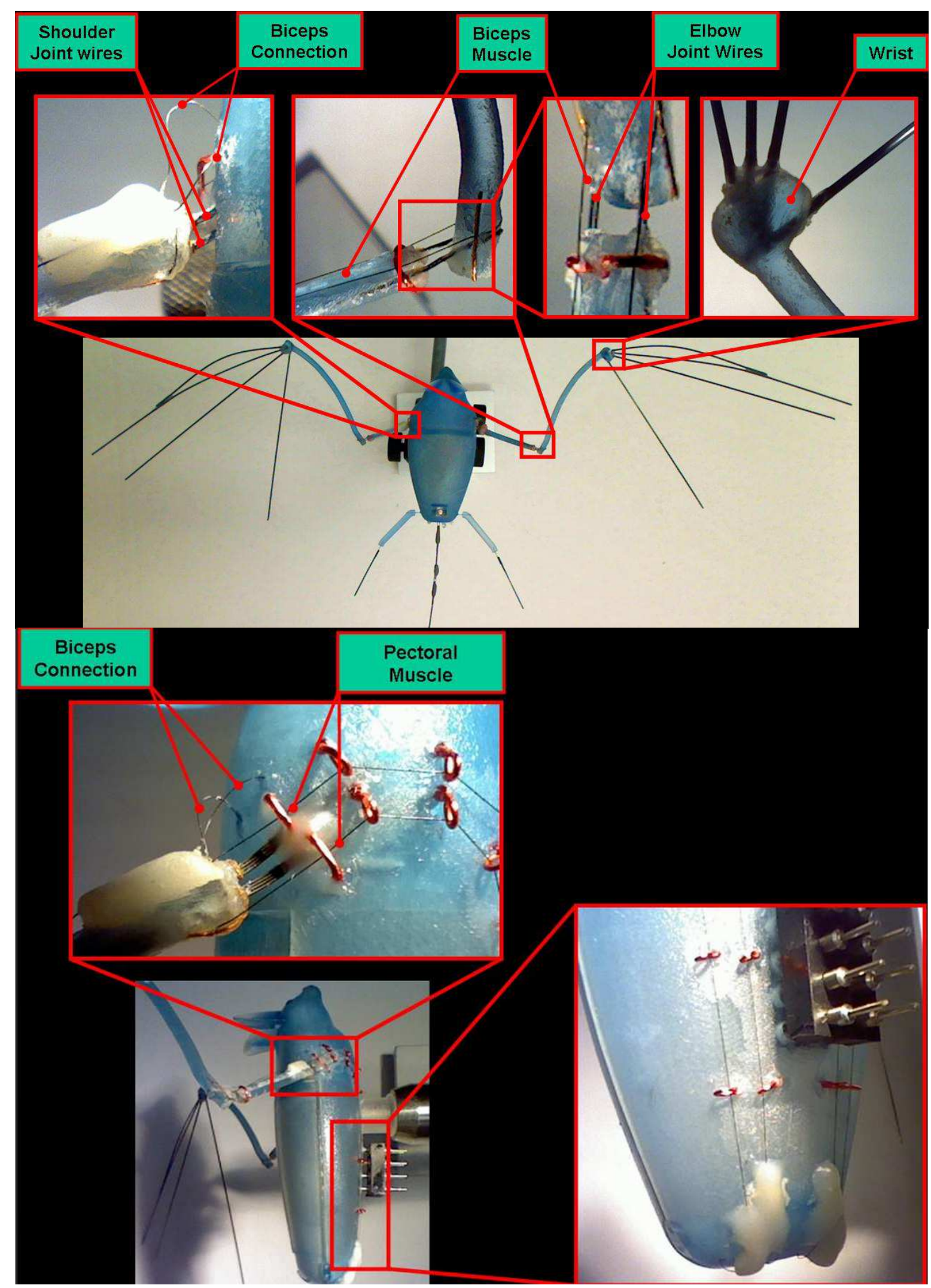

Fig. 11: BATMAV. Dual Role of Shape Memory Alloy wires: as actuation muscles and super elastic joints 

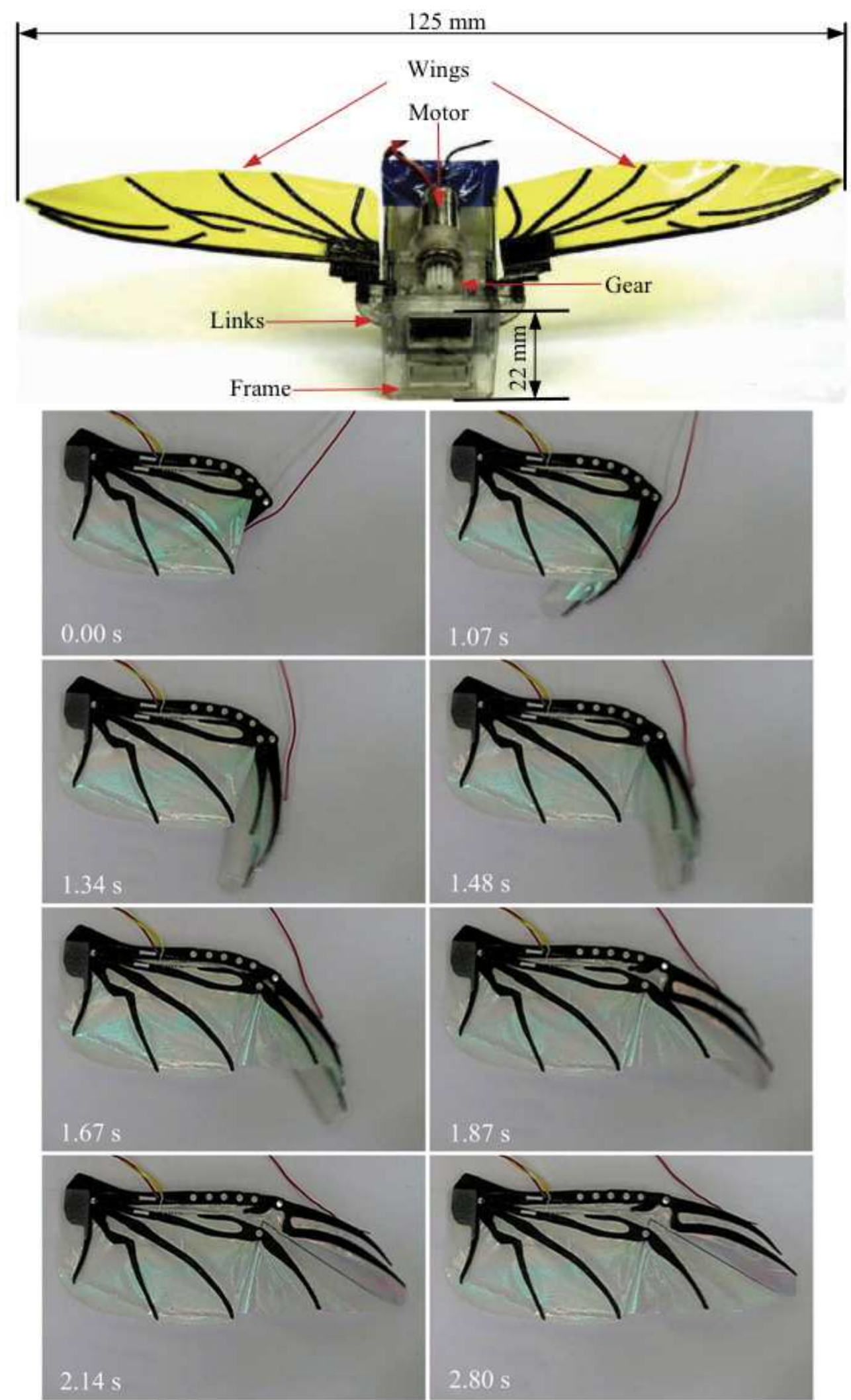

Fig. 12: Prototype of the robotic beetle and detail of the unfolding of the artificial wing 


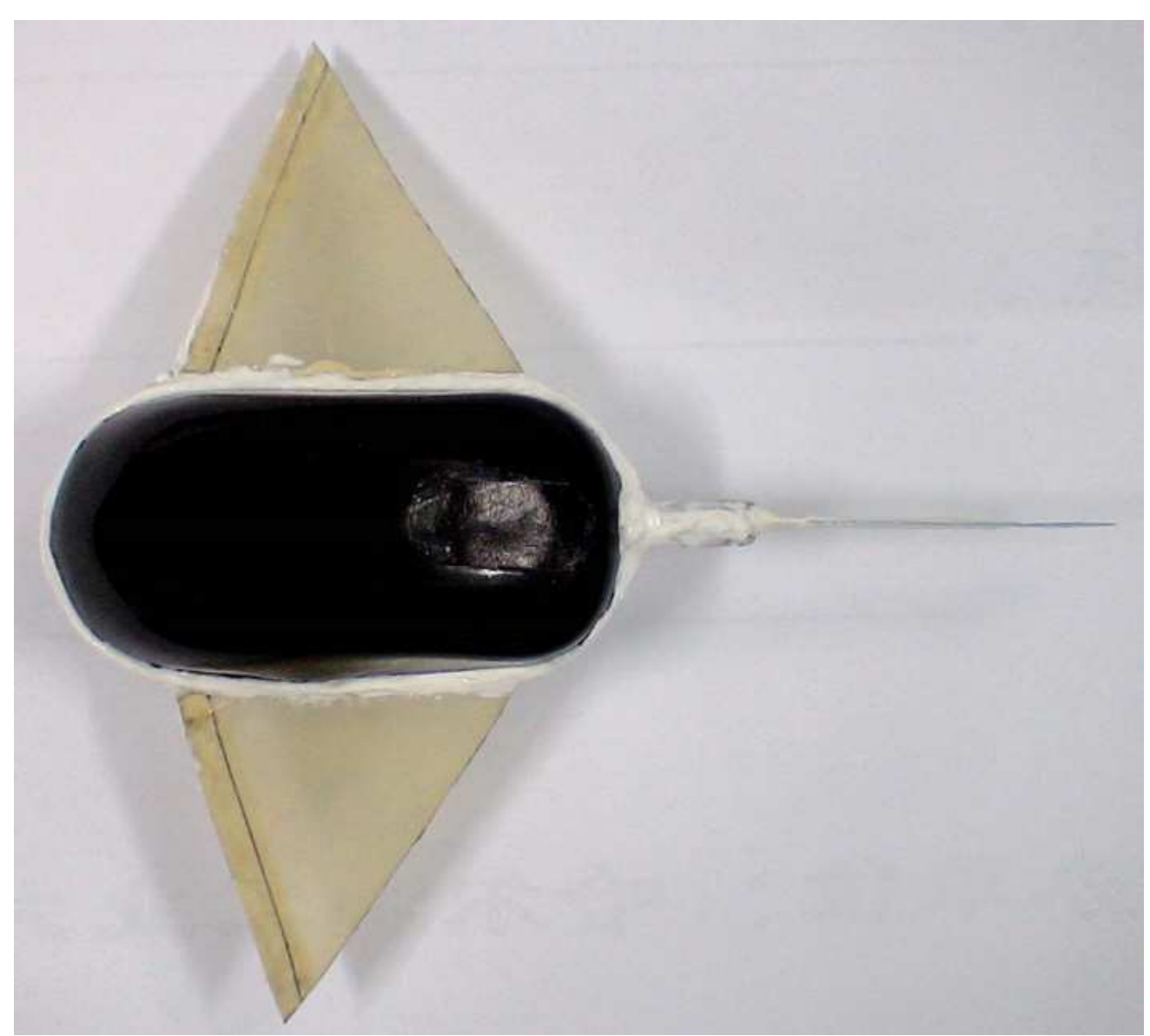

Fig. 13: Micro biomimetic manta ray robot fish

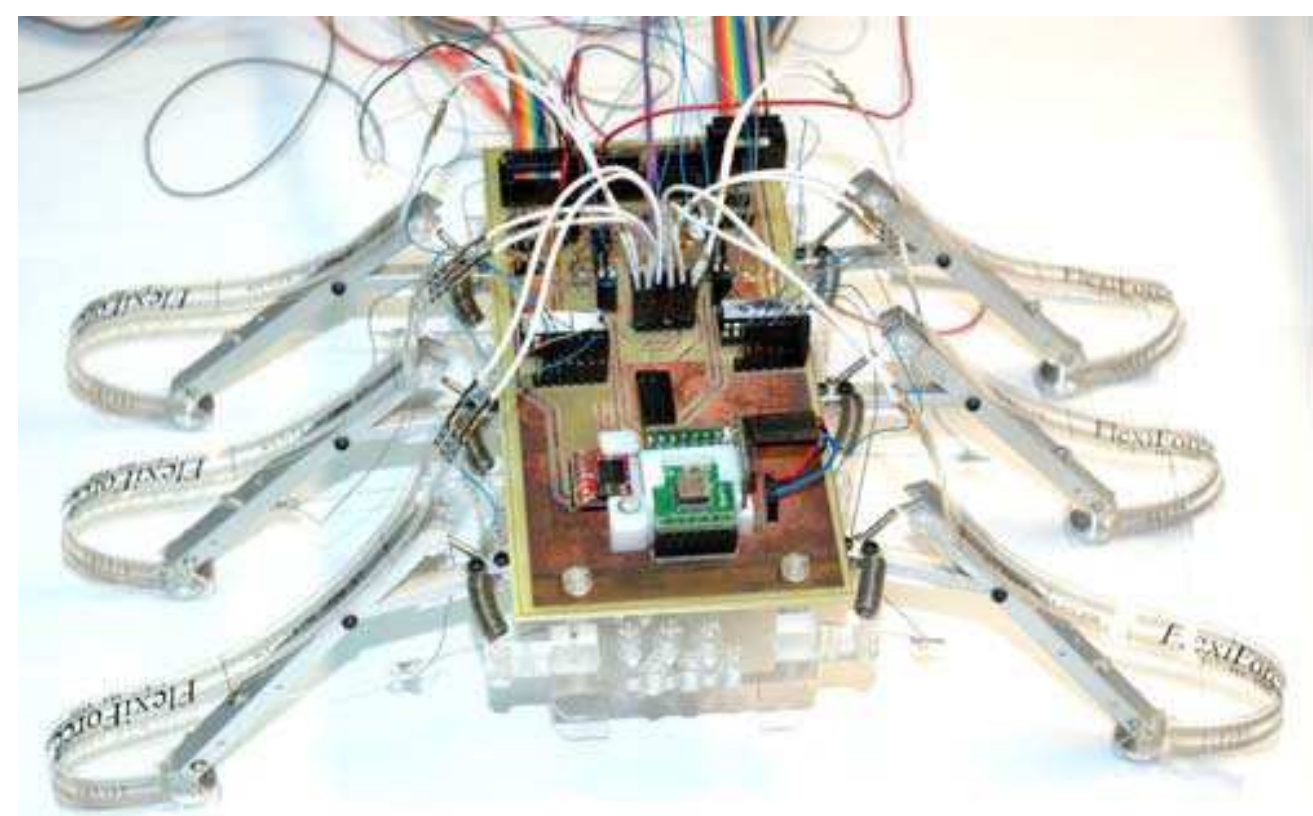

Fig. 14: SMABOT IV, a SMA based hexapod robot with the IMU module, compass sensor and step touch sensors 


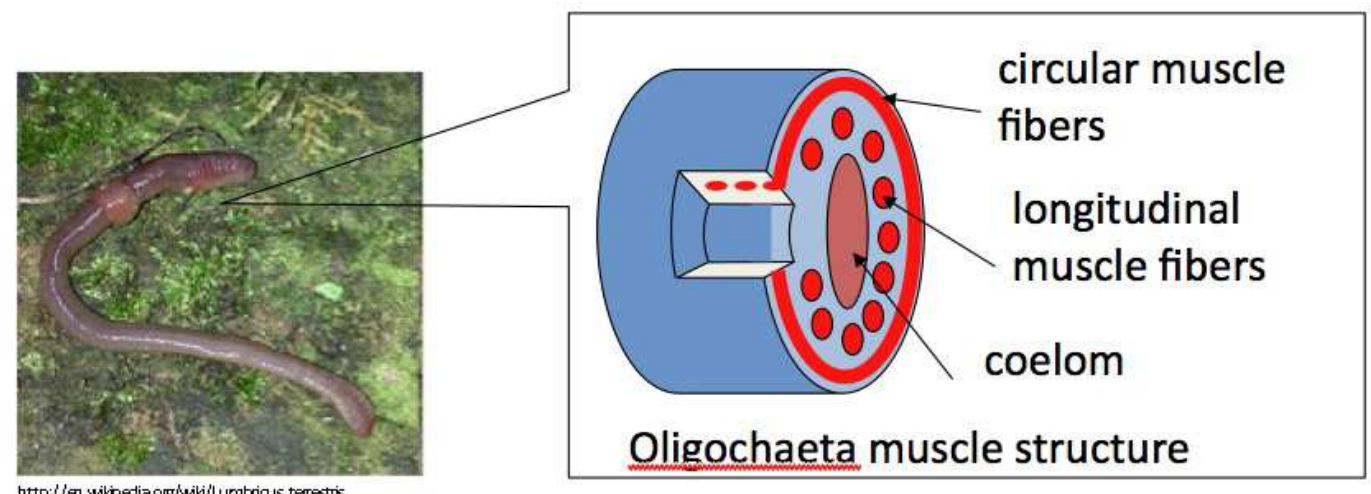

http://en. wilipediaorg/viki/Lumtrious_terederis

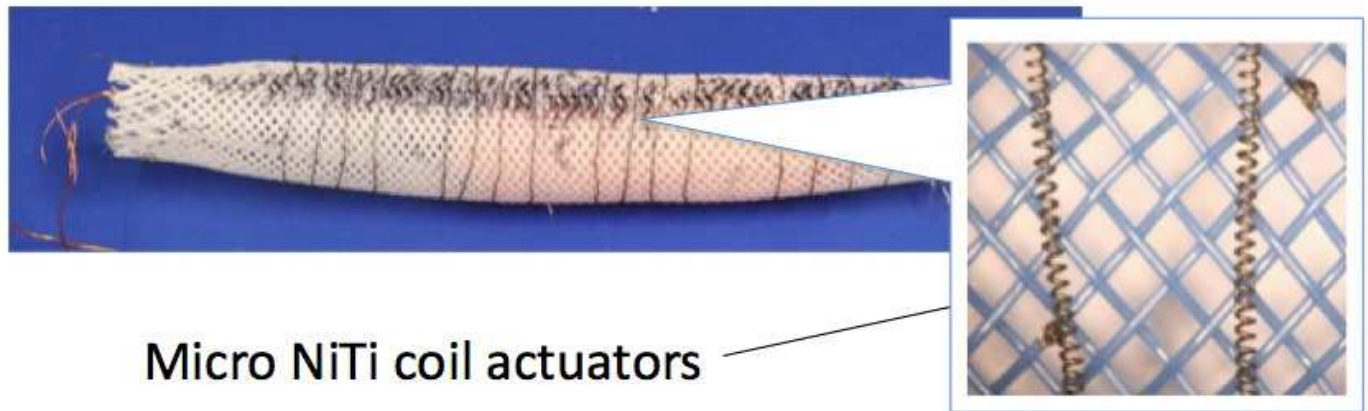

Fig. 15: Arrangement of Antagonistic circular muscles in Oligochaeta

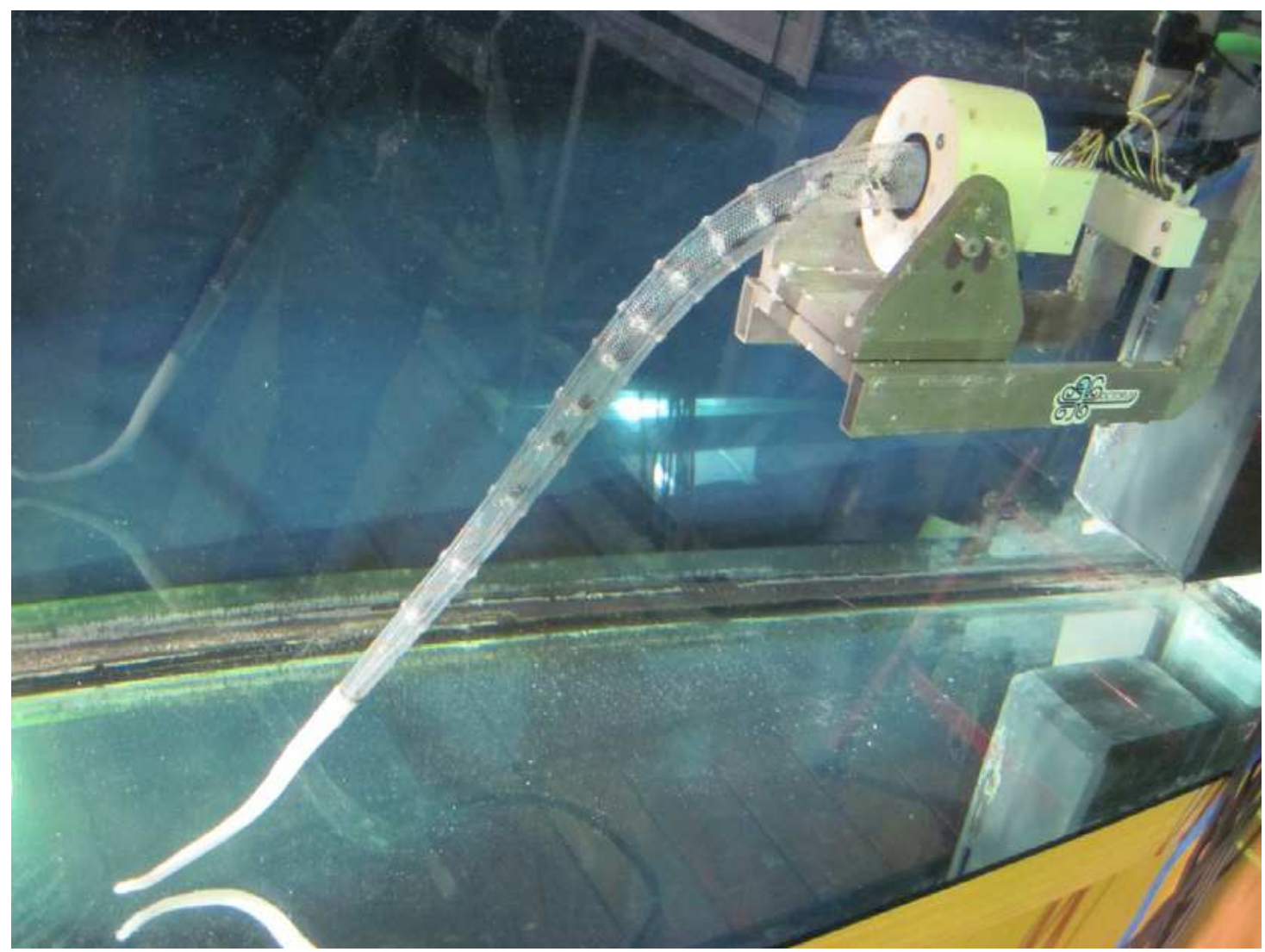

Fig. 16: The SMA-based tentacle 

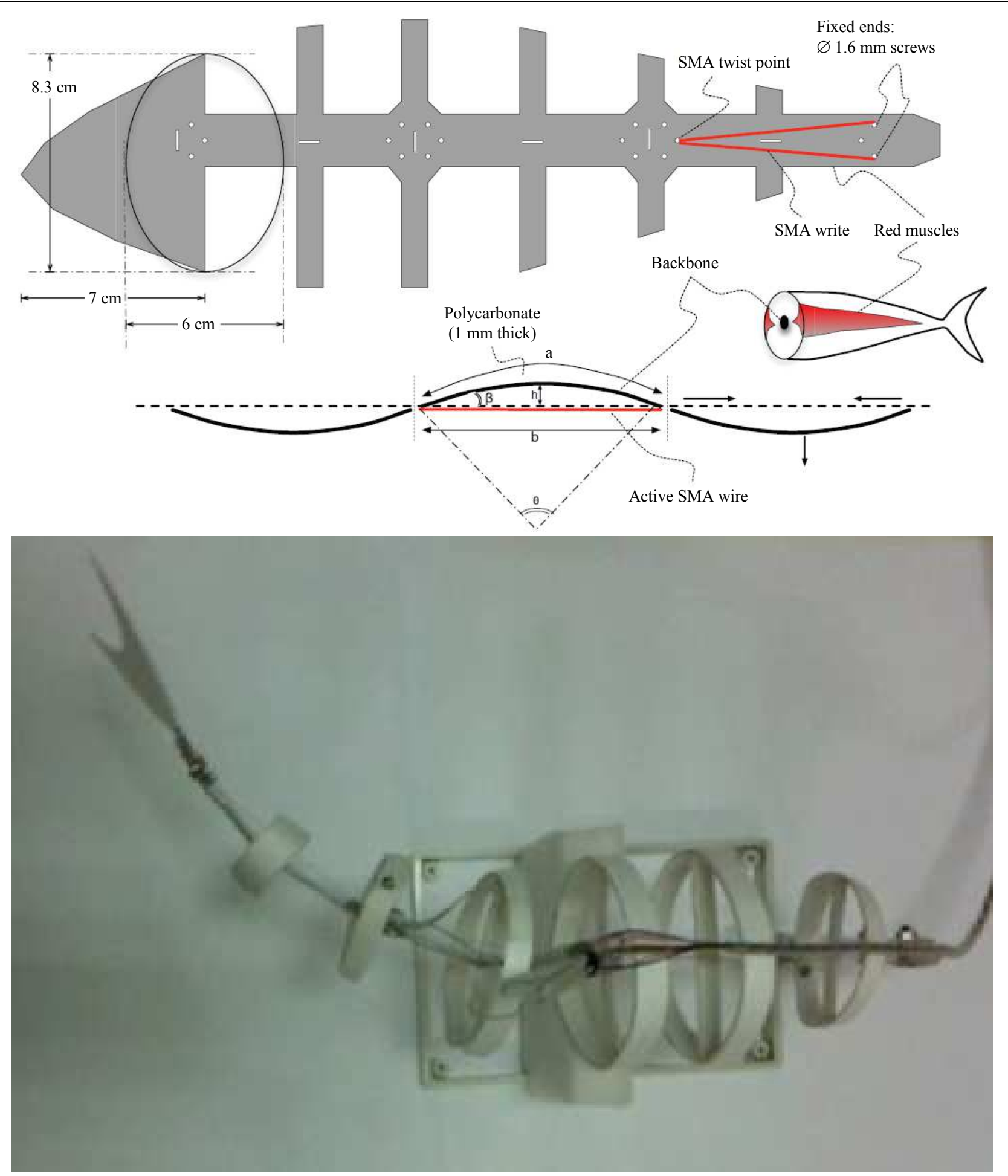

Fig. 17: Main structure of the iTuna robot fish. $\mathrm{a}=8.5 \mathrm{~cm}$. Under nominal operation, $\mathrm{bs} \sim=96 \% \mathrm{a}=8.16 \mathrm{~cm}, \mathrm{~h}=1.02 \mathrm{~cm}, \mathrm{~b}=28$ 。

SMAs typically have a single-form memory effect, also called a memory effect in a simple way manner. The alloy deforms when heated, but cooling does not change if it is not he showed again. The percentage of deformation of NiTi alloys (\% of the strain) is about five percent, much more if it is considered to allow only the deformation of the common steel an average of two percent. Currently, SMA with a bidirectional memory 
effect is also manufactured. In this case, the alloy expands by heating during the transition period temperature and contract spontaneously when it is cooled again below this temperature. To produces double effect of memory, the material being also subjected to a thermal treatment called training. This training phase forces the material to remember both heating and cooling states.

From a microscopic point of view (Fig. 9), all the physical properties of the alloy vary depending on the phase, i.e., from cooling to heating and vice versa. Some of these properties refer to corrosion resistance, elasticity, damping capacity, voltage, electrical resistance and temperature. Therefore, form-memory alloys behave in a thermo-mechanical manner, all of these variables being strongly coupled in a non-linear hysteresis manner.

Figures 10-17 illustrate some existing applications in the field (Coral et al., 2012; Westphal et al., 2011; Nguyen et al., 2010; Wang et al., 2009; Liu and Yen, 2008; Menciassi et al., 2004; Laschi et al., 2012; Rossi et al., 2011).

\section{Conclusion}

A shape memory alloy (also known as smart metal, metal memory, memory alloy, muscle wire, smart alloy) is an alloy that "remembers" its original shape and when it deforms, it returns to the preform when is heated. This material is an easy and solid alternative to conventional drive devices, such as hydraulic, pneumatic and engine systems. The form of memory alloy has applications in industries including automotive, aerospace, biomedical and robotics.

The two main types of memory alloys are copperaluminum-nickel and Nickel-Titanium alloys (NiTi), but SMAs can also be made with zinc, copper, gold and iron alloys. Although iron and copper based SMAs such as Fe-Mn-Si, Cu-Zn-Al and $\mathrm{Cu}-\mathrm{Al}-\mathrm{Ni}$ are commercially available and cheaper than NiTi, NiTi-based SMAs are preferred for most applications due to stability, thermomechanical performance.

SMA can exist in two different phases, with three different crystalline structures (e.g., martensite twinned, martensite detwinned and austenite and six possible transformations.

Figures 10-17 illustrate some existing applications in the field.

\section{Acknowledgement}

The Authors acknowledge Liquid Metals Technologies Inc, Ca USA that kindly supplies the samples for the characterization.

\section{Funding Information}

This research has been funded by Italian Ministry of University and Research project FIRB Future in Research 2008, project RBFR08T83J.

\section{Author's Contributions}

All the authors contributed equally to prepare, develop and carry out this manuscript.

\section{Ethics}

This article is original and contains unpublished material. Authors declare that are not ethical issues and no conflict of interest that may arise after the publication of this manuscript.

\section{References}

Aversa, R., F.I.T. Petrescu, R.V. Petrescu and A. Apicella, 2016a. Biomimetic FEA Bone modeling for customized hybrid biological prostheses development. Am. J. Applied Sci., 13: 1060-1067. DOI:10.3844/ajassp.2016.1060.1067

Aversa, R., F.I.T. Petrescu, R.V. Petrescu and A. Apicella, 2016b. Biofidel FEA modeling of customized hybrid biological hip joint prostheses, part I: Biomechanical behavior of implanted femur. Am. J. Biochem. Biotechnol., 12: 270-276. DOI: 10.3844/ajbbsp.2016.270.276

Aversa, R., F.I.T. Petrescu, R.V.V. Petrescu and A. Apicella, 2016c. Biomimetic finite element analysis bone modeling for customized hybrid biological prostheses development. Am. J. Applied Sci., 13: 1060-1067. DOI: 10.3844/ajassp.2016.1060.1067

Aversa, R., D. Parcesepe, R.V. Petrescu, G. Chen and F.I.T. Petrescu et al., 2016d. Glassy amorphous metal injection molded induced morphological defects. Am. J. Applied Sci., 13: 1476-1482.

DOI: 10.3844/ajassp.2016.1476.1482

Aversa, R., R.V. Petrescu, F.I.T. Petrescu and A. Apicella, 2016e. Smart-factory: Optimization and process control of composite centrifuged pipes. Am. J. Applied Sci., 13: 1330-1341. DOI: 10.3844/ajassp.2016.1330.1341

Aversa, R., F. Tamburrino, R.V. Petrescu, F.I.T. Petrescu and M. Artur et al., $2016 \mathrm{f}$. Biomechanically inspired shape memory effect machines driven by muscle like acting NiTi alloys. Am. J. Applied Sci., 13: 1264-1271. DOI: 10.3844/ajassp.2016.1264.1271

Aversa, R., FIT. Petrescu, R.V.V. Petrescu and A. Apicella, 2016g. Flexible stem trabecular prostheses. Am. J. Eng. Applied Sci., 9:1213-1221. DOI: 10.3844/ajeassp.2016.1213.1221 
Aversa, R., R.V.V. Petrescu, A. Antonio and F.I.T. Petrescu, 2016h. Physiologic human fluids and swelling behavior of hydrophilic biocompatible hybrid ceramopolymeric materials. Am. J. Eng. Applied Sci., 9: 962-972. DOI: 10.3844/ajeassp.2016.962.972

Aversa, R., R. Sorrentino and A. Apicella, 2016i. Biomechanically active ceramic-polymeric hybrid scaffolds for tissue engineering. Proceedings of the International Conference on Biological Sciences and Technology, (BST' 16), Atlantis Press, pp: 308-318.

Aversa, R., R.V.V. Petrescu, A. Apicella and F.I.T. Petrescu, 2017a. Nano-diamond hybrid materials for structural biomedical application. Am. J. Biochem. Biotechnol., 13: 34-41.

Aversa, R., D. Parcesepe, R.V. Petrescu, F. Berto and G. Chen et al., 2017b. Processability of bulk metallic glasses. Am. J. Applied Sci., 14: 294-301. DOI: 10.3844/ajassp.2017.294.301

Aversa, R., R.V. Petrescu, A. Apicella and F.I.T. Petrescu, 2017c. Modern transportation and photovoltaic energy for urban ecotourism. Transylvanian Rev. Administrat. Sci., 13: 5-20.

DOI: $10.24193 /$ tras.SI2017.1

Aversa, R., R.V. Petrescu, F.I.T. Petrescu and A. Apicella, 2018. Nanodiamond for structural biomimetic scaffolds. MSCE, 6: 6-17.

DOI: $10.4236 / \mathrm{msce} .2018 .64002$

Biewener, A.A. and T.J. Roberts, 2000. Muscle and tendon contributions to force, work and elastic energy savings: A comparative perspective. Exerc. Sport Sci. Rev., 28: 99-107.

Coral, W., C. Rossi, J. Colorado, D. Lemus and A. Barrientos, 2012. SMA-based muscle-like actuation in biologically inspired robots: A state of the art review, smart actuation and sensing systems Giovanni Berselli. IntechOpen. DOI: 10.5772/50209

Duerig, T.W., 1990. Engineering Aspects of Shape Memory Alloys. 1st Edn., Butterworth-Heinemann, London, England, ISBN-10: 0408040653, pp: 499.

Hanlon, J.E., S.R. Butler and R.J. Wasilewski, 1967. Effect of martensitic transformation on the electrical and magnetic properties of NiTi. Trans. Metallurgical Society AIME, 239: 1323-1327.

Harrison, J.D., D.E. Hodgson, 1975. Use of TiNi in Mechanical and Electrical Connectors. In: Shape Memory Effects in Alloys. Perkins, J. (Ed.), Springer Science \& Business Media, Boston, MA, ISBN-10: 1468422111.

Huang, X., G.J. Ackland and K.M. Rabe, 2003. Crystal structures and shape-memory behaviour of NiTi. Nat. Mater., 2: 307-311: DOI: 10.1038/nmat884

Kauffman, G.B. and I. Mayo, 1993. Memory metal. ChemMatters, 381: 130-136.

Knowles, K.M. and D.A. Smith, 1981. Acta metallurgica. Materialia, 29: 101-110.
Kus, K. and T. Breczko, 2010. DSC-investigations of the effect of annealing temperature on the phase transformation behaviour in $\mathrm{Ni}-\mathrm{Ti}$ shape memory alloy. Mater. Phys. Mechan., 9: 75-83

Lahoz, R. and J.A. Puértolas, 2004. Training and twoway shape memory in NiTi alloys: Influence on thermal parameters. J. Alloys Compounds, 381: 130-136. DOI: 10.1016/j.jallcom.2004.03.080

Laschi, C., M. Cianchetti, B. Mazzolai, L. Margheri and M. Follador et al., 2012. Soft Robot Arm Inspired by the Octopus, Advanced Robotics, 26: 709-727.

Lindstedt, S., 2016. Skeletal muscle tissue in movement and health: Positives and negatives. J. Experi. Biol. 219: 183-188.

Liu, S.H. and J.Y. Yen, 2008. Sensor fusion in a SMAbased hexapod bio-mimetic robot. Proceedings of the Workshop on Advanced robotics and Its Social Impacts, IEEE, pp: 1-6.

Matsumoto, O., S. Miyazaki, K. Otsuka and H. Tamura, 1987. Acta metallurgica. Materialia, 35: 2137-2144.

Meisel, N.A., A.M. Elliott and C.B. Williams, 2014. A procedure for creating actuated joints via embedding shape memory alloys in PolyJet 3D printing. J. Intelligent Mater. Syst. Structures, 26: 1498-1512. DOI: $10.1177 / 1045389 X 14544144$

Melton, K.N. and O. Mercier, 1980. The mechanical properties of NiTi-based shape memory alloys. Acta Metallurgica, 29: 393-398. DOI: 10.1016/0001-6160(81)90165-6

Menciassi, A., S. Gorini, G. Pernorio and P. Dario, 2004. A SMA actuated artificial earthworm. Proceedings of the IEEE International Conference on Robotics and Automation (ICRA'04) pp: 3282-3287.

Mirsayar, M.M., V.A. Joneidi, R.V. Petrescu, F.I.T. Petrescu and F. Berto, 2017. Extended MTSN criterion for fracture analysis of soda lime glass. Eng. Fracture Mechan., 178: 50-59.

DOI: 10.1016/j.engfracmech.2017.04.018

Miyazaki, S., S. Kimura, K. Otsuka, Y. Suzuki, 1984. The habit plane and transformation strains associated with the martensitic transformation in TiNi single crystals. Scripta Metallurgica, 18: 883-888. DOI: 10.1016/0036-9748(84)90254-0

Naresh, C., P.S.C. Bose and C.S.P. Rao, 2016. Shape memory alloys: A state of art review. IOP Conf. Mater. Sci. Eng., 149: 1-14. DOI:10.1088/1757-899X/149/1/012054

Nguyen, Q., H. Park, D. Byun and N. Goo, 2010. Recent progress in developing a beetle-mimicking flapping-wing system, World Automation Congress (WAC), pp: 1-6.

Nikolaev, V.I., S.A. Pul'nev, G.A. Malygin, V.V. Shpeizman and S.P. Nikanorov, 2008. Generation and relaxation of reactive stresses in a $\mathrm{Cu}-\mathrm{Al}-\mathrm{Ni}$ shape memory alloy upon cyclic temperature variation in the range 293-800 K. Phys. Solid State, 50: 2170-2174. DOI: 10.1134/S1063783408110279 
Otsuka, K., T. Sawamura and K. Shimizu, 1971. Crystal structure and internal defects of equiatomic TiNi martensite. Phys. Stat. Solid, 5: 457-470.

Otsuka, K. and X. Ren, 1999. Recent developments in the research of shape memory alloys. Intermetallics, 7: 511-528. DOI: 10.1016/S0966-9795(98)00070-3

Otsuka, K., C.M. Wayman, K. Nakay, H. Sakamoto and K. Shimizu, 1976. Superelasticity effects and stressinduced martensitic transformations in $\mathrm{CuAlNi}$ alloys. Acta Metallurgica, 24: 207-226. DOI: 10.1016/0001-6160(76)90071-7

Petrescu, F.I.T., E. Buzea, L. Nănuţ, M. Neacşa and C. Nan, 2015. The role of antioxidants in slowing aging of skin in a human, analele univers. Craiova Biol. Horticultura Tehnolo. Prel. Prod. Agric. Ing. Med., 20: 567-574.

Petrescu, RV., R. Aversa, A. Apicella, S. Li and G. Chen et al., 2016a. Something about electron dimension. Am. J. Applied Sci., 13: 1272-1276. DOI: 10.3844 /ajassp.2016.1272.1276

Petrescu, R.V., R. Aversa, A. Apicella, F. Berto and S. Li et al., 2016b. Ecosphere protection through green energy. Am. J. Applied Sci., 13: 1027-1032. DOI: 10.3844/ajassp.2016.1027.1032

Petrescu, F.I.T., A. Apicella, R.V. Petrescu, SP. Kozaitis and R.B. Bucinell et al., 2016c. Environmental protection through nuclear energy. Am. J. Applied Sci., 13: 941-946.

DOI: 10.3844 /ajassp.2016.941.946

Petrescu, F.I.T. and JK. Calautit, 2016a. About nano fusion and dynamic fusion. Am. J. Applied Sci., 13: 261-266. DOI: 10.3844/ajassp.2016.261.266

Petrescu, F.I.T. and J.K. Calautit, 2016b. About the light dimensions. Am. J. Applied Sci., 13: 321-325. DOI: 10.3844/ajassp.2016.321.325

Pittaccio, S., L. Garavaglia, C. Ceriotti and F. Passaretti, 2015. Applications of shape memory alloys for neurology and neuromuscular rehabilitation. J. Funct. Biomater, 6: 328-344.

DOI: $10.3390 / \mathrm{jfb} 6020328$

Priadko, A.I., V.I. Nikolaev, S.A. Pulnev, S.I. Stepanov and A.V. Rogov et al., 2017. Shape memory $\mathrm{Cu}-$ Al-Ni single crystals for application in rotary actuators. Mater. Phys. Mechan. 32: 83-87.

Rossi, C., J. Colorado, W. Coral and A. Barrientos, 2011. Bending continuous structures with SMAs: A novel robotic fish design, Bioinspiration Biomimetics.

Shaw, J.A., C.B. Churchill and M.A. Iadicola, 2008. Tips and tricks for characterizing shape memory alloy wire: Part 1-differential scanning calorimetry and basic phenomena. Society Experi. Mechan., 32: 55-62. DOI: 10.1111/j.1747-1567.2008.00410.x

Šittner, P., L. Heller, C.C. Pilch, A. Thiery and D. Favier, 2014. Young's modulus of austenite and martensite phases in superelastic NiTi wires. J. Mater. Eng. Performance, 23: 2303-2314.

DOI: $10.1007 / \mathrm{s} 11665-014-0976-\mathrm{x}$
Sofla, A.Y.N., D.M. Elzey and H.N.G. Wadley, 2008. Two-way antagonistic shape actuation based on the one-way shape memory effect. J. Intelligent Mater. Syst. Structures, 19: 1017-1027.

Van Humbeeck, J., 2010. Introduction to shape memory alloys. Proceedings of the School and Symposium on Smart Structural Systems Technologies, (SST' 10), Porto, Portugal, pp: 3-23.

Velázquez, R. and E.E. Pissaloux, 2012. Modelling and temperature control of shape memory alloys with fast electrical heating. Int. J. Mechan. Control, 13: 1-8.

Viscuso, S. and S. Pittaccio, 2012. Design and implementation of a portable a magnetic shape memory rotary actuator. J. Intell. Mater. Syst. Struct., 24: 454-472.

Wang, Z., Wang, Y., Li, J. \& Hang, G., 2009. A micro biomimetic manta ray robot fish actuated by SMA, 2009 IEEE International Conference on Robotics and Biomimetics (ROBIO), IEEE, pp. 1809-1813.

Westphal, A., N.F. Rulkov, J. Ayers, D. Brady and M. Hunt, 2011. Controlling a lamprey-based robot with an electronic nervous system. Smart Structures Syst., 8: 39-52.

Xiangyang, H., J. Graeme, J. Ackland and K.M. Rabe, 2003. Crystal structures and shape-memory behaviour of NiTi. Nat. Mater., 2: 307-311. DOI: $10.1038 / \mathrm{nmat} 884$

Yang, J.H. and C.M. Wayman, 1992. Self-accomodation and shape memory mechanism of $\epsilon$-martensite-I. Experimental observations. Mater. Characterizat., 28: 23-35. DOI: 10.1016/1044-5803(92)90026-E

Yang, H.Z., X.G. Duan and H. Deng, 2013. A study on the force distribution for artificial antagonistic muscles. Applied Mechan. Mater., 278-280: 105-110.

Ziólkowski, A., 2012. On analysis of DSC curves for characterization of intrinsic properties of NiTi shape memory alloys. Proceedings of the 12th International Symposium on Physics of Materials, Sept. 4-8, Prague, Czech Republic.

\section{Source of Figures}

Fig. 10: Source: Westphal et al. (2011)

Fig. 11: Source: Picture from https://sites.google.com/site/gheorghebunget/research/ba tmav

Fig. 12: Source: Nguyen et al. (2010)

Fig. 13: Source: Wang et al. (2009)

Fig. 14: Source: Liu and Yen (2008)

Fig. 15: Source: Menciassi et al., 2004 (Image of the real Oligochaeta from http://en.wikipedia.org/wiki/Lumbricus_terrestris).

Fig. 16: Source: Laschi et al. (2012)

Fig. 17: Source: Rossi et al. (2011) 